\title{
Pathogenic landscape of transboundary zoonotic diseases in the Mexico-US border along the Rio Grande
}

\section{Maria Dolores Esteve-Gassent ${ }^{1}{ }^{\dagger}{ }^{\dagger}$, Adalberto A. Pérez de León ${ }^{2 \dagger}$, Dora Romero-Salas ${ }^{3}$, Teresa P. Feria-Arroyo ${ }^{4}$, Ramiro Patino ${ }^{4}$, Ivan Castro-Arellano ${ }^{5}$, Guadalupe Gordillo-Pérez ${ }^{6}$, Allan Auclair ${ }^{7}$, John Goolsby $^{8}$, Roger Ivan Rodriguez-Vivas ${ }^{9}$ and Jose Guillermo Estrada-Franco ${ }^{10}$}

1 Department of Veterinary Pathobiology, College of Veterinary Medicine and Biomedical Sciences, Texas A\&M University, College Station, TX, USA

2 USDA-ARS Knipling-Bushland U.S. Livestock Insects Research Laboratory, Kerrville, TX, USA

${ }^{3}$ Facultad de Medicina Veterinaria y Zootecnia, Universidad Veracruzana, Veracruz, México

${ }^{4}$ Department of Biology, University of Texas-Pan American, Edinburg, TX, USA

${ }^{5}$ Department of Biology, College of Science and Engineering, Texas State University, San Marcos, TX, USA

${ }^{6}$ Unidad de Investigación en Enfermedades Infecciosas, Centro Médico Nacional SXXI, IMSS, Distrito Federal, México

${ }^{7}$ Environmental Risk Analysis Systems, Policy and Program Development, Animal and Plant Health Inspection Service, United States Department of Agriculture, Riverdale, MD, USA

${ }^{8}$ Cattle Fever Tick Research Laboratory, United States Department of Agriculture, Agricultural Research Service, Edinburg, TX, USA

${ }^{9}$ Facultad de Medicina Veterinaria y Zootecnia, Cuerpo Académico de Salud Animal, Universidad Autónoma de Yucatán, Mérida, México

${ }^{10}$ Facultad de Medicina Veterinaria Zootecnia, Centro de Investigaciones y Estudios Avanzados en Salud Animal, Universidad Autónoma del Estado de México, Toluca, México

\section{Edited by:}

Juan-Carlos Navarro, Universidad Central de Venezuela, Venezuela

\section{Reviewed by:}

Jingjing Ye, Food and Drug

Administration, USA

Eduardo Rebollar-Tellez, Universidad

Autonoma de Nuevo Leon, Mexico

\section{*Correspondence:}

Maria Dolores Esteve-Gassent

Department of Veterinary

Pathobiology, College of Veterinary

Medicine and Biomedical Sciences,

Texas A\&M University, TAMU-4467,

College Station, TX 77843, USA

e-mail: mesteve-gassent@

cvm.tamu.edu

${ }^{\dagger}$ Maria Dolores Esteve-Gassent and Adalberto A. Pérez de León have contributed equally to this

manuscript.
Transboundary zoonotic diseases, several of which are vector borne, can maintain a dynamic focus and have pathogens circulating in geographic regions encircling multiple geopolitical boundaries. Global change is intensifying transboundary problems, including the spatial variation of the risk and incidence of zoonotic diseases. The complexity of these challenges can be greater in areas where rivers delineate international boundaries and encompass transitions between ecozones. The Rio Grande serves as a natural border between the US State of Texas and the Mexican States of Chihuahua, Coahuila, Nuevo León, and Tamaulipas. Not only do millions of people live in this transboundary region, but also a substantial amount of goods and people pass through it everyday. Moreover, it occurs over a region that functions as a corridor for animal migrations, and thus links the Neotropic and Nearctic biogeographic zones, with the latter being a known foci of zoonotic diseases. However, the pathogenic landscape of important zoonotic diseases in the south Texas-Mexico transboundary region remains to be fully understood. An international perspective on the interplay between disease systems, ecosystem processes, land use, and human behaviors is applied here to analyze landscape and spatial features of Venezuelan equine encephalitis, Hantavirus disease, Lyme Borreliosis, Leptospirosis, Bartonellosis, Chagas disease, human Babesiosis, and Leishmaniasis. Surveillance systems following the One Health approach with a regional perspective will help identifying opportunities to mitigate the health burden of those diseases on human and animal populations. It is proposed that the Mexico-US border along the Rio Grande region be viewed as a continuum landscape where zoonotic pathogens circulate regardless of national borders.

Keywords: Lyme borreliosis, VEE, Hantavirus, Babesia, Chagas, Leishmania, pathogenic landscapes, global change

\section{INTRODUCTION}

The United States (US) and Mexico share a border spanning $3,100 \mathrm{~km}$ from the Gulf of Mexico to the Pacific Ocean. Approximately 14 million people reside within the area found roughly $100 \mathrm{~km}$ on either side of the international line between the two countries, with 7.3 million residing in the US and 6.8 million in Mexico (1). A bi-national effort is in place to protect the environment and public health in the US-Mexico border region that is consistent with sustainable development. The sector encompassing the border States of Texas, Tamaulipas, Nuevo León, and Coahuila includes at least 29 municipalities on the Mexican side and 168 cities and towns on the US side, covers portions of the Southern Texas Plains and Western Gulf Coastal Plain ecoregions of Texas, and lies within a zoonotic disease hotspot (1-3). It appears that conditions leading to the emergence of zoonotic diseases as a public health threat in the US and other parts of the world may be at play in the transboundary region covering south Texas and Northeast Mexico (4-7). Among these factors, we have poverty. For instance, in southern US, $16.5 \%$ of the population is in poverty, and $22 \%$ of children under 18 years old live in such conditions in the same region [National Center for children in poverty ${ }^{1}$ (8)]. Texas has a poverty level (17.6\%) higher than the national average (15\%) calculated as a 3-year average. In addition, recent

${ }^{1}$ http://www.nccp.org 
studies showed that migrants displaced due to adverse weather conditions related to climate change, are predicted to increase during the twenty-first century $(9,10)$. Economically, deficient areas will be highly impacted with these types of extreme weather events, making this population more vulnerable to emerging infectious diseases due to an increase in out-migration flow (9).

These scenarios acquire special relevance in the US-Mexico border, one the largest and longest-sustained routes of human migration. From the human migratory standpoint, the States of Chiapas and Tabasco in Mexico play a vital role as transit points for large numbers of people. In this regard, the ports of entry are the Ocosingo and Tapachula surroundings in Chiapas, and Tenosique in Tabasco. Veracruz is therefore the transition point for the nearly 400,000 individuals, representing approximately 50 nationalities, who traverse Mexico each year with the ultimate goal of reaching the US (Migration Department, Mexican Interior Ministry 2006). All these individuals are forced to cross areas that might be "hot spots" of Babesiosis, Venezuelan equine encephalitis virus (VEEV), and other pathogens that have incubation periods fluctuating between 3 and 10 days (3). Consequently, the "One Health" approach is required to enhance the ability to recognize zoonotic pathogens in humans, domestic, and wildlife reservoirs and the associated vectors in the US and Mexico transboundary region. This concept states simply that clinicians, researchers, agencies, and governments must work together seamlessly for the benefit of animal and human health as well as for the welfare of the global environment.

An international perspective on the interplay between disease systems, ecosystem processes, land use, and human behaviors is applied in this review paper to analyze landscape and spatial features of Venezuelan equine encephalitis (VEE), Hantavirus disease, Lyme disease (LD), Leptospirosis, Bartonellosis, Chagas disease, Babesiosis, and Leishmaniasis all of which can be considered, or have the potential to be emerging zoonotic infectious diseases of relevance in this transboundary region (Table 1) (11-15).

\section{PATHOGENIC LANDSCAPE \\ GLOBAL CHANGE AND EMERGENCE OF VECTOR-BORNE ZOONOTIC DISEASES}

As the world globalizes in terms of Nation's economies and increased travel, borders are opened for a constant flow of goods, products, and pathogen dissemination. Likewise, as human populations expand into new geographical regions, the possibility that humans will come into close contact with infectious agents' potential hosts, which can transmit pathogens to human beings, increases. Such factors, combined with increased human density and mobility, stand as a serious human health threat. Additionally, climate change is increasingly becoming a concern in the emergence of zoonotic infectious diseases (16). For the past 70 years, most of the newly emergent diseases have been identified as zoonoses (60.3\% of EIDs), and the majority $(71.8 \%)$ has originated in wildlife (17). Thus, according to the transboundary zoonotic disease concept, understanding how these pathogens emerge in different geographical regions will directly benefit global trade and public health. Here, we review several diseases that could impact a geographically strategic region in the US and Mexico border area. Insights gained understanding the pathogenic landscape of these zoonotic diseases could help enhance predictive tools, which might be applied to study the epidemiology of other transboundary pathogens. Pathogenic landscape is a term used to describe attributes of an ecosystem that influence spatial variations in disease risk or incidence (18).

Emission of greenhouse effect gasses has impacted global climate (19), increasing Earth's surface temperature $0.74^{\circ} \mathrm{C}$ on average (20). According to the 2002 World Health Organization (WHO) report, climate change has caused approximately five million disability-adjusted life years (DALYs) in the world (21). Moreover, the 2007 Intergovernmental Panel on Climate Change report (22) and the 2014 National Climate Assessment by the US Global Research Program (16), suggest that climate change will affect North America at multiple levels, such as public health, agriculture, water supply, and frequency of extreme weather events, among others (15). Increased temperatures, sea levels, precipitations, and droughts due to climate change can drastically change the epidemiology of vector-borne diseases $(15,21,23,24)$, as both vectors and pathogens are very sensitive to these climatic variables.

Climate change can potentially alter the spatial range of vectorborne diseases through shifts in geographical distributions of their vectors $(14,25,26)$. Despite some positive developments, such as better access to clean drinking water, lower exposure to insect vectors, and higher-quality housing, projected changes in climate over the next decades may exacerbate infectious disease incidence even in developed regions such as North America (15). Habitat changes, alterations in water storage and irrigation habits, pollution, development of insecticide and drug resistance, globalization, tourism, and travel are additional factors that may aggravate this threat (26). For instance, in Europe, short winters appear to have influenced populations of Dermacentor reticulatus, the tick vector responsible for transmission of Babesia canis, to expand to the East (20). In Veracruz, Mexico, a study found an association between an increase in dengue cases and increased temperature and rainfall that followed El Niño Southern Oscillation (ENSO) events (27). Increased rainfall could create both microclimates, in which vectors can thrive, as well as cause high temperatures, which could allow for a rapid increase in vector densities and ultimately put humans at risk for vector-borne disease. Extreme-flooding events can cause outbursts of zoonotic diseases caused by infectious agents transmitted by rodents, as their pathogen-containing urine contaminates the water. This was the case in Nicaragua, in which a Leptospirosis epidemic followed a flooding event (28). Thus, humans might face increasing exposure to zoonotic diseases as naturally occurring phenomena like ENSO and flooding events are expected to become frequent due to climate change (23). In addition, climate change can also affect the epidemiology of zoonoses indirectly. For instance, the density of vegetation in a particular area increases during heavy rainfall seasons. This vegetation indirectly supports the reproduction of rodents, which can be infected with pathogens transmissible to humans (29).

Human migration and economic trade can exacerbate climate change influences on vector-borne diseases along the TexasMexico border. Ecological niche models, under climate change scenarios, showed an increased distribution of Leishmaniasis vectors and reservoirs in Texas and North Mexico (14). A recent study in the Texas-Mexico border identified the present and future 
Table 1 | Transboundary zoonotic diseases, distribution, agents, vectors, and transboundary relevance in the US-México border region

\begin{tabular}{|c|c|c|c|c|}
\hline Disease & Distribution $^{a}$ & Etiologic agent & Vector & Transboundary relevance \\
\hline \multicolumn{5}{|l|}{ VIRUS } \\
\hline VEE & $\begin{array}{l}\text { Meso-America, } \\
\text { Southern Texas, and } \\
\text { Northern Mexico }\end{array}$ & $\begin{array}{l}\text { Venezuelan equine } \\
\text { encephalitis virus }\end{array}$ & $\begin{array}{l}\text { Culex (Melanoconion) taeniopus } \\
\text { Deinocerites pseudes } \\
\text { Aedes (Ochlerotatus) taeniorhynchus } \\
\text { Mammalophilic mosquitoes }\end{array}$ & $\begin{array}{l}\text { Shared vectors and reservoirs } \\
\text { Human migration } \\
\text { Livestock movement }\end{array}$ \\
\hline \multicolumn{5}{|l|}{ BACTERIA } \\
\hline Lyme disease & US, Mexico, Canada & Borrelia burgdorferi & $\begin{array}{l}\text { Ticks } \\
\text { Ixodes scapularis } \\
\text { I. pacificus }\end{array}$ & $\begin{array}{l}\text { Shared vectors and reservoirs } \\
\text { Different public health policies }\end{array}$ \\
\hline $\begin{array}{l}\text { Rocky mountain } \\
\text { spotted } \\
\text { fever/Brazil } \\
\text { spotted fever }\end{array}$ & $\begin{array}{l}\text { US, Mexico, Canada, } \\
\text { Costa Rica, Panama, } \\
\text { Colombia, Uruguay, } \\
\text { Argentina, Brasil }\end{array}$ & Rickettsia rickettssi & $\begin{array}{l}\text { Ticks } \\
\text { Dermacentor variabilis } \\
\text { D. andersoni } \\
\text { Rhipicephalus sanguineus } \\
\text { Amblyomma cajennense } \\
\text { Haemaphysalis leporispalustris }\end{array}$ & Shared vectors and reservoirs \\
\hline Bartonellosis ${ }^{b}$ & $\begin{array}{l}\text { Americas, Europe, } \\
\text { Asia }\end{array}$ & $\begin{array}{l}\text { Bartonella henselae } \\
\text { Ba. quintana } \\
\text { Ba. bacilliformi } \\
\text { Ba. vinsonii subsp. } \\
\text { berkhoffii }\end{array}$ & $\begin{array}{l}\text { Ticks } \\
\text { I. pacificus } \\
\text { I. scapularis } \\
\text { I. ricinus } \\
\text { I. persulcatus } \\
\text { D. reticulatus } \\
\text { D. marginatus } \\
\text { R. sanguineus } \\
\text { R. microplus } \\
\text { Sand flies } \\
\text { Lutzomyia verrucarum } \\
\text { L. columbiana } \\
\text { L. peruensis } \\
\text { Lice }{ }^{\mathrm{C}} \\
\text { Pediculus humanus humanus } \\
\text { P. capitis } \\
\text { Fleas } \\
\text { Pulex irritans }\end{array}$ & $\begin{array}{l}\text { Shared vectors and reservoirs } \\
\text { Human migration } \\
\text { Livestock movement } \\
\text { Poverty (poor sanitation, hygiene and } \\
\text { crowded housing environments) }\end{array}$ \\
\hline
\end{tabular}


Table 1 | Continued

\begin{tabular}{|c|c|c|c|c|}
\hline Disease & Distribution $^{a}$ & Etiologic agent & Vector & Transboundary relevance \\
\hline \multicolumn{5}{|l|}{ PROTOZOA } \\
\hline Human & US & Babesia microti & Ticks & Shared vectors and reservoirs \\
\hline \multirow[t]{4}{*}{ Babesiosis } & & & I. scapularis & \\
\hline & & & I. pacificus & \\
\hline & & & 1. texanus & \\
\hline & & & D. variabilis & \\
\hline \multirow[t]{4}{*}{ Chagas $^{d}$} & American Continent & Trypanosoma cruzi & Triatoma sanguisuga & Shared vectors and reservoirs \\
\hline & & & T. gerstaeckeri & Human migration \\
\hline & & & T. lenticularia & Different public health policies \\
\hline & & & & Poverty (suboptimal housing) \\
\hline \multirow[t]{3}{*}{ Leishmaniasis } & Americas & Leishmania & Lutzomyia sand flies & Shared vectors and reservoirs \\
\hline & & (Leishmania) & & Human migration \\
\hline & & Leishmania (Viannia) & & Different public health policies \\
\hline
\end{tabular}

${ }^{a}$ Adapted from Ref. (173).

${ }^{b}$ With relevance to this review paper.

${ }^{c}$ Human body and head lice, and human fleas. Other species have been associated with wildlife and domestic animals (173).

${ }^{d}$ As per Ref. $(298,304)$.

eIn the US only.

potential distribution, under climate change scenarios, of the LD vector, Ixodes scapularis (13). The results of this study indicated that South Texas includes suitable habitat for I. scapularis. In a similar study, the potential future distribution of main Chagas disease vectors, Triatoma gerstaekeri and T. sanguisuga, is expected to increase in the Texas-Mexico border due to climate change (12). Temperature and precipitation played a major role in the models presented in these three studies.

The transboundary region between Mexico and the US is vulnerable to outbreaks of vector-borne diseases because some Southern States, such as Texas, share a legacy of neglected tropical diseases (NTD) (30) with Mexico. This situation highlights the urgency to develop and deploy active surveillance programs, which are necessary for optimal management and control of vector-borne diseases.

\section{EFFECT OF EXOTIC WEEDS ON VECTOR POPULATIONS}

Invasive weeds can change the ecology of, and induce a pathogenic landscape in which arthropod-borne disease transmission can increase. Mack and Smith (31) link invasive plants as catalysts for the spread of human parasites by documenting the escape and mast seed production of Asian frost-tolerant bamboos from cultivation in the Pacific Northwest to potential outbreaks of the omnivorous deer mouse Peromyscus maniculatus that carries Hantavirus. Invasive weeds also interact with ticks. Japanese barberry has been shown to increase the abundance of the blacklegged tick, I. scapularis and the infection prevalence of Borrelia burgdorferi (LD) $(32,33)$. In India, Kyasanur forest disease of cattle and monkeys is attributed to disturbance of the native forest for tea plantations, which resulted in invasions of the invasive weed Lantana camara and outbreaks of Haemaphysalis spiniger, the vector for Kyasanur encephalitis-inducing virus within the flavivirus group (34). The clearing of the native forest in Argentina and the transition to exotic African grasses increased the impact of cattle fever ticks (CFT) by increasing the encounter rate with cattle (35). This same pathogenic landscape phenomenon appears to be happening in the permanent quarantine zone (PQZ) in the TexasMexico border region, with the invasion of the exotic and invasive weed species, Arundo donax known as the giant reed (Figure 1). Aerial remote sensing pictures of the Rio Grande taken in 2002 indicate that $62 \%$ or 5981 ha of riparian habitat on Rio Grande from Big Bend to Falcon Dam was infested with giant reed, which includes most of the PQZ (36). Zoonotic agents are not transmitted by CFT, but knowledge from the study of CFT ecology can be applied to understand how ecosystem shifts can influence spatial variation in disease risk or incidence for tick-borne disease systems of public health importance.

Giant reed impacts the USDA-APHIS Cattle Fever Tick Eradication Program (CFTEP) along the transboundary region of Texas-Mexico border. Giant reed indirectly affects CFT because survival is highest in giant reed as compared to native riparian vegetation or buffel grass pastures (37). Abiotic conditions within giant reed stands are cooler due to the heavy shade and high rates of evapotranspiration (ET), which appears to be cause of lower levels of CFT mortality. Biotic conditions in giant reed stands are also altered because the abundance of CFT arthropod predator species is reduced (37). In a review of the literature records of predation on ticks, Samish \& Alekseev (38) documented that ground dwelling predators (e.g., ants, beetles, and spiders) are the major natural enemies of ticks. Preliminary pitfall trap surveys in the PQZ indicate that ground dwelling beetle populations, specifically the predaceous Carabidae and omnivorous Tenebrionidae species, are strongly reduced in giant reed compared to adjacent native plant communities (Goolsby, personal communication). Ants are also known to be important predators of ticks in Texas. Fleetwood et al. (39) documented reduced populations of Lone Star ticks, 

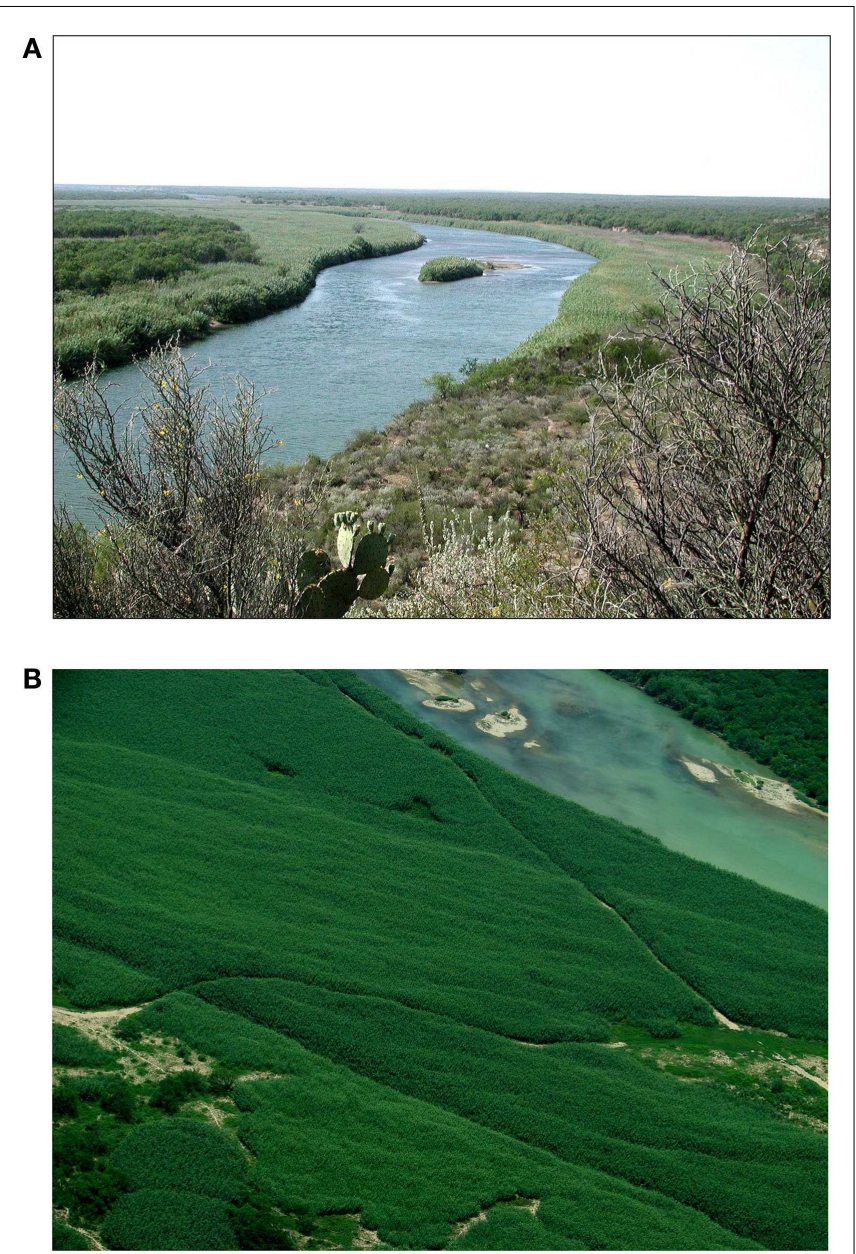

FIGURE 1 | Invasion of exotic Arundo donax, giant reed, is facilitating the invasion of Cattle Fever Ticks in the transboundary region by creating a microclimate that is favorable for its survival. (A) Arundo donax on Rio Grande near Eagle Pass, TX, USA. (B) Arundo donax on Rio Grande near Del Rio, TX, USA.

Amblyomma americanum, in pastures with abundant red imported fire ants, Solenopsis invicta. Fire ant predation is generally believed to reduce the incidence of tick-vectored pathogens of livestock. In Louisiana, fire ant predation of Ixodes ticks was associated with a reduced incidence of Anaplasmosis in cattle (40). Preliminary studies in the PQZ found that ant diversity and abundance is low in giant reed stands, with the red imported fire ant, Solenopsis invicta, being the most common species. Comparative studies are needed to survey ant diversity throughout the PQZ to investigate their potential impact on CFT. Control of exotic giant reed and restoration of the native riparian vegetation could reduce the favorability of this habitat for CFT and lead to restoration of a more intact leaf litter insect predator community and in total a more robust biological barrier to invading CFT and other tick-borne zoonoses. Giant reed may also be creating a localized climatic refuge for CFT when conditions in the upland habitat are not favorable for survival. As giant reed declines, lower ET rates, increased ground temperatures, and lower humidity levels are expected in these riparian habitats and these conditions are known to reduce the survival of larval and adult CFT (41-45). Giant reed also indirectly impacts the CFTEP by reducing visibility in the PQZ along the Rio Grande. Heavy infestations of giant reed make it extremely difficult for mounted inspectors to detect and capture stray livestock.

Exotic weeds interact with disease vectors in the transboundary region between Texas and Mexico. These weeds create a landscape that is depauperate of beneficial predators of disease vectors and alter the microclimate, and as such, they can facilitate the invasion of these vectors and must be considered in their full ecological context.

\section{ZOONOTIC INFECTIOUS DISEASES VIRAL INFECTIOUS DISEASES Venezuelan equine encephalitis}

Venezuelan equine encephalitis viruses are members of the VEE complex and comprise the three major serogroups of New World alphaviruses $(46,47)$. Fourteen subtypes and varieties have been described within the VEEV complex (48). The IAB and IC viruses are designated "epidemic" or "epizootic" because they have been isolated only during equine and human outbreaks. They are distinct from enzootic strains (subtypes/varieties ID-F, II-VI) that circulate in sylvatic or swamp habitats, and occasionally cause disease in humans or domestic animals (48-50). Importantly, VEEV isolates identified to be of the IE subtype identified during epizootics in Mexico appear to be equine neurovirulent, but are unknown to produce high titer viremia (50). Transmission cycles have been described for most of the enzootic VEE subtypes/varieties [ID, IE, II, IIIA, and IIIB (Tonate)], except III $\mathrm{C}$ and $\mathrm{V}$ (48). Most of them are transmitted among rodents by mosquitoes in the subgenus Culex (Melanoconion) and few mammalophilic mosquitoes (51).

Venezuelan equine encephalitis virus was known to be circulating and producing illness in horses since the 1920s $(49,51)$, and in 1938 the virus was isolated from the brain of a horse that died of encephalitis in South America (52-54). Human cases with neurological complications were recorded in 1950 during an outbreak of febrile illness in Espinal, Colombia (55). VEEV outbreaks continued at regular intervals through the 1960s in South America affecting tens-to hundreds-of-thousands of people $(50,56)$. Between 1973 and 1992 no VEEV was documented, which led to the assumption that the epidemic-epizootic subtypes IAB and IC VEEV had disappeared (50). However, phylogenetic studies and renewed epidemic/epizootic VEE activity in Northwestern Venezuela during 1992-1993 revealed that these viruses remain a threat $(57,58)$. Two equine epizootics in the States of Chiapas and Oaxaca, Mexico caused by a subtype IE virus (59), and a major outbreak in Venezuela and Colombia during 1995 affecting about 100,000 people $(60,61)$ draw attention to the continued threat of VEEV. To date, VEEV viruses affecting humans and equids have been found in at least 12 countries of the Americas causing important social and economic damage mainly in Latin America (48).

Most VEEV epizootics and epidemics have taken place in Northern South America and in regions of Venezuela and Colombia. However, VEE has also affected North America on several occasions. In 1966, an equine epizootic in Northeastern Mexico 
was reported in southern Tamaulipas and Northern Veracruz within the Panuco river basin (62). Although no viruses were isolated, VEE etiology was determined serologically. The lack of VEE vaccination in Mexico at this time suggests that this outbreak was caused by a local enzootic subtype IE strain. Another major Middle American outbreak and one of the most devastating VEEV pandemics of the Continent, began near the Guatemala-El Salvador border on the Pacific coast and spread through much of Central America, Mexico, and Texas during 1969-1972, and involved tensof-thousands of equines and people. In Mexico, equine deaths from VEE were first reported in 1969 in mountainous regions of the State of Chiapas close to the Guatemalan border (63). By 1970, the epizootic had produced about 10,000 equine deaths in the States of Chiapas and Oaxaca (64). The outbreak then spread northward to the Gulf Coast and eventually reached Southern Texas. In Texas, approximately 1500 horses died of VEE, and several hundred human infections were documented. The Texas outbreak was halted by a massive equine vaccination program and aerial insecticide spraying costing about 15 million dollars $(50,65)$.

In the 1990s, two outbreaks of equine encephalitis occurred on the Pacific Coast of Southern Mexico. From June to July in 1993, 125 equine cases including 63 deaths were reported in Chiapas State. Three years later, from June to July in 1996, another equine epizootic occurred nearby in Oaxaca State, involving 32 horses with 12 deaths $(59,66)$. Epidemiological and serological data were consistent with VEE, and VEEV was isolated from encephalitic horses involved in each outbreak. No human cases were documented during these outbreaks. However, further serosurveys and VEEV isolations obtained in the same area of the 1990s outbreaks demonstrated that VEE has been endemic in this Southern region of Mexico for decades (67).

Two virus isolates from the Mexican outbreaks of the 90s were examined antigenically and genetically. All were VEE subtype IE by IFA and ELISA using monoclonal antibodies (68). Sequencing and phylogenetic studies indicated that the outbreak strains belong to one of three major subtype IE VEEV lineages. This lineage circulates on the Pacific Coast of Guatemala, and was sampled there from 1968 to $1980(59,66)$. The absence of previous Mexican isolates from this lineage suggests that the currently circulating Mexican strains originated from enzootic transmission foci on the Pacific Mexican Coast. The remaining IE lineages circulate on the Gulf and Caribbean Coasts of Central America (Nicaragua northward to the Gulf Coast of Mexico and close to the US border) and in Western Panama, and differ by up to $7 \%$ at the nucleotide sequence level.

Before the Chiapas-Oaxaca outbreaks, isolates of enzootic VEEV, including subtype IE, were traditionally believed to be avirulent for equines, and were not previously known to have epizootic potential (69-71). Experimental infection of horses with several IE strains from Mexico and Nicaragua showed that these viruses generally produced little viremia and disease $(70,71)$. Further studies using reverse genetics approaches demonstrated that Aedes (Ochlerotatus) taeniorhynchus, an abundant epizootic vector in coastal areas of Chiapas and Oaxaca, was more susceptible to isolates obtained during the 1993 and 1996 epizootics compared with closely related enzootic IE strains isolated previously in Guatemala (72). A mechanism of VEEV emergence was suggested showing that a single Ser $\rightarrow$ Asn amino acid substitution at position 218 of the E2 envelope glycoprotein was the major determinant of the increased Ae. taeniorhynchus infectivity. Viral adaptation to a vector that prefers to bite large mammals was suggested as the emergence mechanism in the 1990s outbreaks of Southern Mexico (72).

Subtype IE enzootic viruses are the only VEEV known to continuously circulate in Mexico both currently as well as prior to 1993 outbreak. They occur from Western Panama through Tamaulipas State in Mexico $(48,65,73-75)$. The ecology of the IE viruses has been studied in detail and Culex (Melanoconion) taeniopus is the known primary enzootic vector of subtype IE viruses in Guatemala (76), and one of the principal vectors maintaining endemic VEEV cycles in southern Mexico, the Gulf Coast of Mexico (48, 73, 75), and Panama (65). It has been demonstrated that $C x$. taeniopus found in estuarine areas of Chiapas is susceptible to both subtype IE VEEV isolates from the Pacific Mexican outbreaks of the 90s and to strains isolated from hamster sentinels during the $2000 \mathrm{~s}$ in the same region (77). Cx. taeniopus feeds on a wide variety of hosts, mainly small rodents from the Cricetidae family such as cotton rats and rice rats, and seems to circulate subtype IE VEEV not only in the Mexican Pacific Coast but also in the Gulf Coast of Mexico $(73,77)$. The scenario in the Pacific Coast of Southern Mexico appears to involve VEEV transmission by Ae. taeniorhynchus to equids and possibly humans at inland locations (48). The threat of VEEV outbreaks in the Mexican Pacific region involving enzootic and epizootic vectors exists (48). Such region is linked to the East through Gulf river basins where several endemic VEEV foci are found, along the States of Tabasco, Veracruz, and Tamaulipas. The later of these States is adjacent to the US Texas border, and is a spot of subtype IE VEEV activity (73). Hotspot activity was characterized through serosurveys suggesting VEEV infections in cattle, equines, rodents, and humans, which was complemented with the isolation of IE VEEV (73). Findings of the study showed that at least one major urban region (Minatitlan in the State of Veracruz) has active enzootic VEEV transmission with Cx. taeniopus identified as the main VEEV vector (74; EstradaFranco and Weaver, unpublished information). Several mosquito epizootic vectors of VEEV that were found infected and active during the VEEV pandemic of the 1970s are present on both sides of the border (Tamaulipas and Texas), such as Ae. sollicitans, Psorophora confinnis, and Ae. taeniorhynchus $(63,78)$. The risk of Ae. taeniorhynchus or other epizootic vectors adapting to endemic VEEV cycles elsewhere outside the Chiapas area, as was demonstrated with the IE VEEV strains isolated in the Pacific coast, could be of veterinary and public health significance. An epidemic strain of VEEV has the potential to arise from circulating endemic strains, which may be easily misdiagnosed for another febrilecausing disease if appropriate diagnostic assays are not routinely performed. The movement of epidemics by viremic individuals is a major concern, particularly in the Gulf Coast region of Mexico, which could threaten previously unaffected areas of Mexico and even the US. Moreover, direct human-to-human transmission of VEEV has also been suggested by the sudden appearance, rapid increase, and brief occurrence of human disease within affected communities $(61,79)$. 
Reconstructing the historical incidence of VEE could facilitate the forecast of recurring patterns and help improve strategies for disease prevention, e.g., vaccine distribution logistics. Our hypothesis is that drivers of VEE outbreaks are responsive to heavy rainfall events but activity subsides as drier conditions return.

The historical time-series shows three repeating VEE outbreaks over the past century, recurring at approximately 30 -year intervals, and spanning up to one decade. The gap of two decades following each outbreak period is conspicuous (Figure 2). Attention to details of each major outbreak show striking differences between epidemics. The first event (Outbreak I, 1935-1946) is exclusively an equine outbreak, with a locus in Columbia and Venezuela. By 1942, it had spread to Peru in the South and by 1943 to Trinidad in the East. The actual number of equines affected in this outbreak was not documented, and there are no records of human VEE cases; the latter do not appear as recorded observations until the 1960-decade. The gaps over the 1970-1980 decades (Gap b) and over the 1996-2013 interval (Gap c) contrast, at least in terms of recent serological evidence, and in terms of important climatic conditions.

The ocean indicators both show low levels of storm impact over the 1972-1992 (Gap b), and likely reflect the paucity of extreme rainfall events, which is in contrast with the high storm levels over the 1996-2013 interval (Gap c) (Figure 2). The latter suggests hurricane and ENSO events are now opportune to bring heavy rainfall into the VEE-affected region. This begs the question of why recent VEE levels remain relatively low and points to the need for further analysis of local rainfall and other weather events across the region.

There is uncertainty and considerable concern over the possible re-emergence of an outbreak of VEE. Our time-series model and its correlation with broad climate signals (Figure 2) offers a new and evocative look at VEE at the century and crossregional scales. It opens a window on a conceptual framework for better understanding and managing outbreaks of the virus through both the tracking of accelerated climate change (e.g., satellite imagery), and use of long-term forecasting (Figure 3). Work is in progress using power spectrum analysis to quantify likely timing and magnitude of future outbreaks. This is important now that serological analyses show the widespread presence of the VEE virus in humans, equines, and populations of virus reservoirs like the rodent species mentioned above, which mosquito vectors feed on, that respond to unusually strong rainfall events.

The development and persistence of high Accumulated Cyclonic Energy Index (ACE) and equatorial Pacific Ocean Southern Oscillation Index (SOI) levels imply VEE outbreak activity currently and in the near future (Figure 2). Why VEE outbreak activity has remained low since 1966, when broad oceanic indicators suggest a high potential for outbreak, remains unknown, which indicates the need for further research. For example, additional research into local rainfall conditions could help understand how mosquito populations expand, which may drive VEEV activity as it has been shown in other mosquito-borne arboviral disease systems (80). Conditions since the 1972-1992 gap have changed, moving toward better virus monitoring and disease management approaches. These changes, taken with the movement of human populations into cities and a relative decline in equine populations, will also play a role in decreasing the likelihood or severity of a VEE outbreak. There is currently widespread mosquito control in response to dengue epidemics. Any of these developments may be limiting the magnitude of current and near-term VEE epidemics (Figure 3). Outbreaks in the 1930s and 1960s were weakly constrained, at best, and may offer a study in contrast to modern conditions with better knowledge and disease management infrastructure.

\section{Hantavirus}

The genus Hantavirus, from the family Bunyaviridae, is composed of viruses with a three-segment negative sense RNA genome (81,

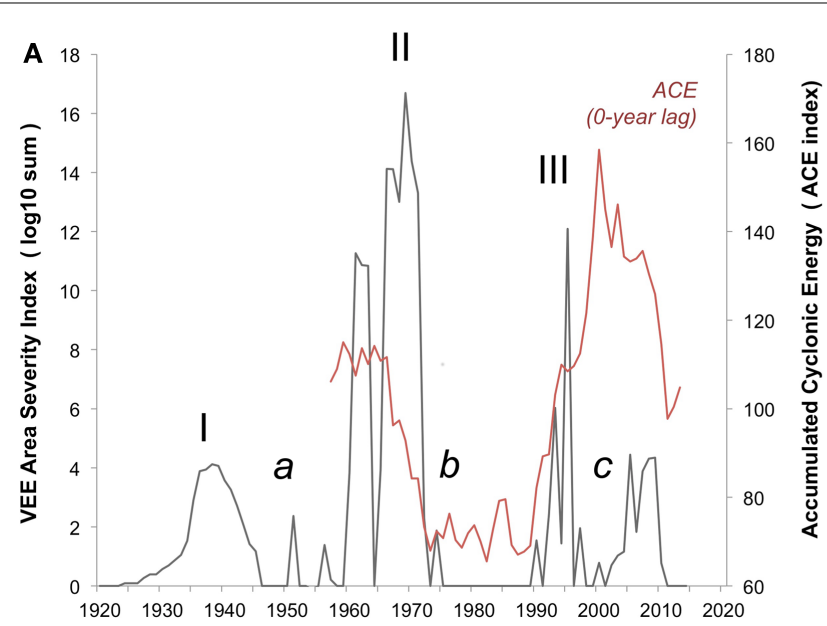

FIGURE 2 | Integrated VEE area-severity index. Integrated VEE area-severity index (dark solid line, left axis) based on historical reconstruction of areal extent and severity in equine and human populations over the 1920 through 2013 period. Three major VEE outbreaks

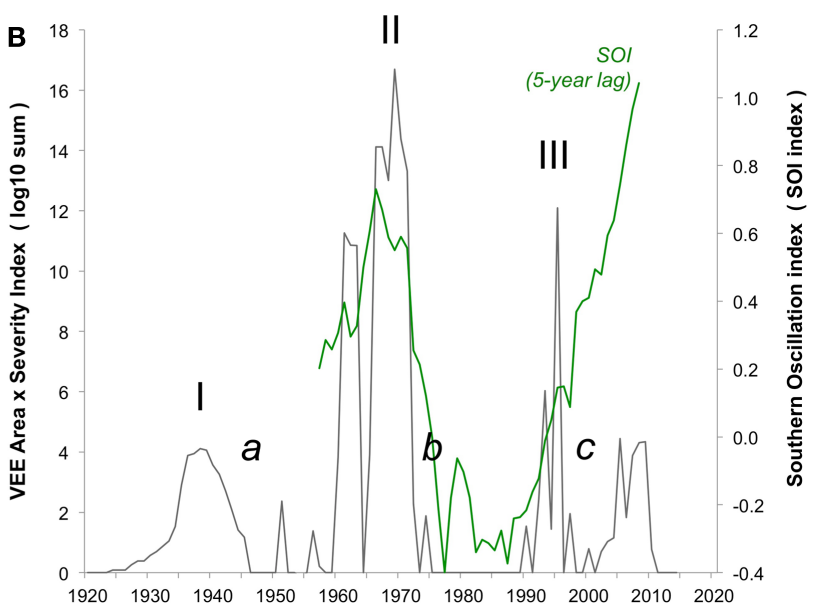

$(\mathrm{I}, \mathrm{II}, \mathrm{III})$ and three gap-intervals $(a, b, c)$ of low VEE are shown. (A) Eleven-year running means of accumulated cyclonic energy index (ACE, red font) and (B) the Southern Oscillation Index (SOI, green font) given on right axis. 


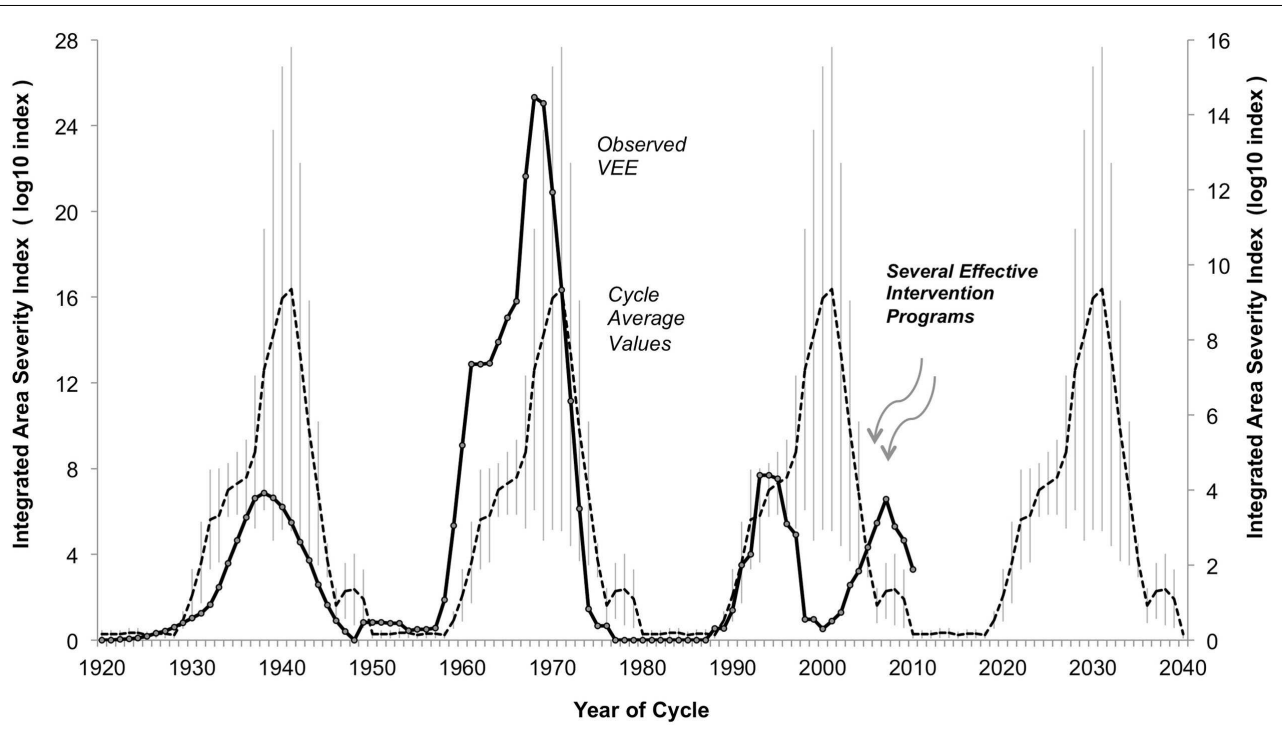

FIGURE 3 | Observed integrated area-severity index for Venezuelan equine encephalitis (VEE) in the Americas, 1920-2010. Integrated Area-Severity (IAS) index (dark solid line, left axis, log10 scale, 5-year point-centered moving average) for Venezuelan Equine Encephalitis (VEE) in the Americas, based on reconstruction of actual disease incidence reported in literature, 1920-2010. Hypothetical reconstruction of expected levels of VEE, 1920-2010, achieved by sequential repeat of the average IAS index levels over
Outbreak Two (1950-1979) and Outbreak Three (1980-2009) (dashed line, right axis, $\log 10$ scale), with standard error of mean added (light vertical lines). Outbreak One (1920-1949) values excluded from average due to lack of solid data. Subdued levels of VEE over Outbreak Three could be the result of assertive mosquito control programs related to dengue fever epidemics, and/or improved VEE management approaches and infrastructure (see text for details).
82). In nature, these viruses are hosted by a variety of rodent and soricomorph species as persistent infections (81). Humans acquire Hantavirus infection by inhaling aerosolized particles from rodent excreta and urine, or via the bite of an infected animal (81). Some rodent-borne Hantaviruses are associated with two types of human disease, differing between the New and Old Worlds. In the Americas, Hantavirus pulmonary syndrome (HPS) has reached fatality rates of $60 \%$ and is characterized by elevated pyrexia, pulmonary dysfunction, and cardiac shock (83). In several regions of the Old World (Europe, Russia, China and Korea), hantaviral infections cause a hemorrhagic fever with renal syndrome (HFRS) characterized by high fever, renal dysfunction, and hemorrhage but with mortality rates usually lower than $12 \%(81,83)$.

A relevant feature of Hantaviruses is their close association between a specific Hantavirus and its rodent host species, suggesting a strong relationship between Hantaviruses and their reservoirs $(84,85)$. Globally, these viruses occur in close association with rodent and shrews of the families Cricetidae and Soricidae, with a majority of New World Hantaviruses detected in reservoir rodent species of the sub-family Neotominae $(82,86)$. Throughout America, more than 30 Hantaviruses have been identified, but only a few have been associated to HPS (81). The New World geographic distribution of known hantaviral strains includes Canada, US, Mexico, Honduras, Costa Rica, Panama, Venezuela, Peru, Bolivia, Brazil, Argentina, Chile, and Paraguay $(81,83)$. Rodents with Hantavirus antibodies have been detected in Peru, Venezuela, Costa Rica, Honduras, and Mexico, although HPS in humans has not been documented in these countries $(81,87)$. The distribution of recorded cases of HPS and the distribution of Hantavirus seroprevalent rodents in the Americas is not coincidental for several reasons: (1) not all Hantaviruses have been associated with HPS; (2) our knowledge of hantaviral diversity present in the continent is likely incomplete; and (3) HPS may be confused with clinically similar diseases. In North America, five Hantaviruses known to cause HPS are the Sin Nombre virus (SNV), New York virus (NYV), Choclo virus (CHOV), Black Creek Canal virus (BCCV), and Bayou virus (BAYV) $(83,88) . \mathrm{SNV}$ is the major cause of HPS in the US and Canada, where Peromyscus maniculatus (deer mouse) is the primary rodent reservoir $(81,89)$.

Northeastern Mexico (Chihuahua, Coahuila, Nuevo León, and Tamaulipas) and Texas share a common biogeographic history, and thus a large number (23) of Cricetinae rodent species are shared among these States $(90,91)$. Because the abiotic environment and rodent assemblages of Northeastern Mexico are similar to those of areas in the adjacent US, it is likely that many viruses circulating in this region occur on both sides of the international border. However, specific information regarding the prevalence and spatial distribution of Hantaviruses within this region is scarce and incomplete. Hantavirus antibody-positive rodents from seven species have been found in Chihuahua, Nuevo León, and Tamaulipas. The only Hantavirus identified to date within these species is the SNV. However, because most of the rodent individuals tested were only analyzed by serology tests, it is possible that other Hantaviruses occur in Northeastern Mexico (88, 92, 93). In Texas, antibodies for Hantaviruses have been detected in 11 rodent species and 4 Hantaviruses (SNV; El Moro Canyon virus, ELMCV; Muleshoe virus, MULV; and BAYV) are known to occur in this state (94). No cases of HPS are known from Mexico, but up to 2006 a total of 28 confirmed cases were recorded in 
Texas. Of these, 24 cases were associated to SNV and 3 to BAYV. Infection with SNV had a high mortality rate of 50\% (12/24), but all of the three patients infected with BAYV survived (95). The geographic distribution of HPS cases in Texas shows the two groups with most cases (64\%) are in the West and Panhandle areas, with the rest of the cases found along the Gulf of Mexico Coast area. This disjoint case distribution is due to rodent reservoir distributions. Cases along the Gulf Coast are associated to the BAYV, which is carried by the rice rat (Oryzomys palustris), whereas the cases in Western Texas have been related to SNV presence in the deer mouse (P. maniculatus) (95). O. palustris is present in Northeastern Mexico, but no seropositive individuals have been reported. Its role as a BAYV reservoir in Mexico is likely minor as the range of this rodent is limited to the extreme Northern corner of Tamaulipas (90). However, two rodent species ( $P$. maniculatus, and the white-footed mouse, Peromyscus leucopus) pose a more serious risk for HPS along the transboundary States. Both species have wide ranges across Texas and Northeastern Mexico; within this region, SNV seroprevalent individuals have been recorded for both species $(88,94,95)$. Moreover, based on the list of Hantaviruses identified in the Southwestern US, it is suggested that four Hantaviruses likely circulate in Northern Mexico: SNV, ELMCV, MULV, and Limestone Canyon virus (LSCV). These viral strains are hosted by rodent species of the Peromyscus, Reithrodontomys, and Sigmodon genera (88), which are ubiquitous throughout the transboundary region. This hypothesis needs to be confirmed with further work to ascertain the public health risk for human populations on both sides of the border. To achieve this goal, it is necessary to determine the geographic distribution patterns of Hantavirus sero-prevalence in rodent reservoir species and understand the mechanistic processes that determine these patterns.

Beyond knowing the specific situation in the Eastern transboundary region between Mexico and the US, further work needs to extend outside of this zone, as it might influence this region. Mexico has a very diverse mammalian fauna ( $~ 525$ species) with rodents comprising almost half (235 spp., 44.8\%) of the species (90). It is possible that many more species harbor Hantaviruses than those currently recognized (88). Specifically, the transboundary region could serve as a connection between Hantaviruses of Neartic origin with others from tropical regions. The State of Tamaulipas has a mammalian fauna that represents a mix of Neartic and Neotropical taxa (90) and the possibility exists that these rodent species of Neotropical affinities could harbor Hantaviruses found in tropical areas such as the Catacama virus (CATV) present in O. couesi from Honduras $(83,87)$. Moreover, evidence of the presence of Hantavirus seropositive rodents in regions of Southern Mexico and crucial human migration crossing pathways are elements to be considered in this complex equation (88). For instance, in the State of Chiapas' coastal and central valleys, there are clear indications for the presence of Hantavirus in wild life. After infection, the resultant disease can take up to 2 weeks to develop in the human host, allowing the disease to move with relatively low detection. Thus, the potential risk of these Neotropical Hantaviruses existing in the transboundary region needs to be evaluated.

\section{BACTERIAL INFECTIOUS DISEASES Tick-borne bacterial infections}

Globally, ticks serve as vectors for a number of zoonotic bacterial pathogens, such as the spirochete Borrelia burgdorferi, the causative agent of LD, as well as the intracellular pathogens Rickettsia rickettsii, Ehrlichia chaffeensis, E. ewiingii, and Anaplasma phagocytophilum (Table 1), also known as tick-borne rickettsial diseases (TBRD) (96). These pathogens are maintained in natural cycles involving wild mammals and several species of hard ticks in the family Ixodidae. Foci of LD exist in the US, Europe, and Asia, and it is considered an emerging infection in those parts of the world (97-101). In the US LD is the most prevalent arthropodborne infection with over 30,000 cases reported to the Centers for Disease Control and Prevention (CDC) in recent years. The increase in LD cases during the last few years has prompted its classification as an emerging infectious disease. Similar to other arthropod-borne diseases, LD is a complex system subject to shifts in ecological processes that influence vector biology and the epidemiology of B. burgdorferi infection in reservoir hosts and humans.

Hard tick species in the genus Ixodes are recognized generally as common vectors of B. burgdorferi. I. scapularis and I. pacificus are known competent vectors in the US, while I. persulcatus and $I$. ricinus are the documented vectors in Eurasia (99, 102105). The pathogen is maintained in the environment by different vertebrate hosts with varying degrees of competence. The main reservoir, the white-footed mouse, Peromyscus leucopus, is found in the forests of Eastern North America $(106,107)$. There is an extensive bibliography on the molecular diversity and adaptation of $B$. burgdorferi to its natural environment, as well as on the impact of species diversity in a particular area on reducing LD risk (108-118). In addition, some of these studies have also considered the effect of climate change on the geographic distribution of $I$. scapularis in addition to its phenology in the US and Canada (119121). Although LD in humans is more prevalent in Northeastern US, the lack of detailed studies in Southern US has prevented comparisons, and evaluations of ecological factors responsible for promoting the differential incidence of LD between these regions. Moreover, in some parts of the world the ecology and epidemiology of LD remain to be fully understood. Thus, LD is considered a transboundary zoonotic disease in that it can reach epidemic proportions in regions of the globe regardless of country borders (122). This is coupled with the fact that there is unequally distributed knowledge about the ecology of this disease among the regions in which it occurs.

Human risk of infection with $B$. burgdorferi across the continental US has been predicted using the density of $I$. scapularis infected nymphs (DIN) $(123,124)$. Under this scenario, Southern US States were considered as a low risk region given the nonappearance of host-seeking I. scapularis nymphs at sampled sites $(123,124)$. In striking contrast to the conclusion of this suggested null risk of acquiring LD in Southern States, a steady number of LD cases have been reported in these low risk areas every year (125, 126). Some of the caveats of these most recent studies include the lack of accounting for both human movement (some cases can be acquired in a region different from the one where they are 
reported) and differences in tick phenology between geographic areas (124). These limitations might explain why the models utilized cannot explain the variation in distribution of the disease observed in low incidence areas. Drivers for the variation in distribution of disease cases observed in low incidence areas remain to be identified.

In Mexico, a national serosurvey of human serum samples reported a $B$. burgdorferi sero-prevalence of $1.1 \%$ (127). The Mexican States of Tamaulipas, Nuevo León and Coahuila in the Texas-Mexico border region presented the highest sero-prevalence (6.4\%) for the country (128). Also, Ixodes ticks infected with B. burgdorferi sensu stricto occur in the same States (129), and recently the infection has been documented in white-tailed deer (130). Distribution models of potential tick vectors in Mexico point to a wide distribution range that overlaps not only Northeastern Mexican States along the border with the US, but also extend to central Mexico $(131,132)$. These studies, together with confirmed clinical cases of LD acquired in parks near Mexico City $(133,134)$, demonstrate the existence of a zoonotic cycle responsible for LD in Mexico.

TBRD are a group of zoonoses clinically similar, yet epidemiologically and etiologically distinct. In the US, these diseases include: (1) Rocky Mountain spotted fever (RMSF), (2) human monocytic ehrlichiosis (HME), (3) human granulocytic anaplasmosis (HGA) (135), (4) Ehrlichia ewingii infection, and (5) other emerging TBRD (Table 1). TBRD are common occurrences in the medical and veterinary clinical setting, and are gaining more attention from physicians and veterinarians since TBRD continue to cause severe illness and death in otherwise healthy individuals $(136,137)$. The epidemiology of these diseases reflects the geographic distribution and seasonal activities of vectors and reservoirs and human behavior that places persons at risk for infection through tick bite $(13,129,137,138)$. Environmental changes may alter the distribution of wild animals and arthropod vectors, which could extend their range to areas close to human populations where these pathogens could be transmitted (13). But demographic and sociologic factors also play a critical role in determining disease incidence.

Several ticks species are vectors of different rickettsiae causing TBRD. $R$. rickettsii, the causative agent of RMSF, is transmitted most frequently by the American dog tick (Dermacentor variabilis) in the Eastern, Central, and Pacific coastal US and the Rocky Mountains, while the wood tick (D. andersoni) transmits this pathogen in the Western US. The brown dog tick (Rhipicephalus sanguineus), a vector of RMSF in Mexico (129, 137, 139), was implicated in 2005 as vector of this disease in a confined geographic area in Arizona (140). Rhipicephalus ticks from Mexicali, Mexico have been recently genetically characterized, and found to be different from those isolated in the US (141). The cayenne tick (Amblyomma cajennense) is a common vector for RMSF in Central and South America (129, 132, 142), and its range extends into the US through Texas. Ehrlichia chaffeensis and Ehrlichia ewingii are transmitted to humans by the lone star tick (Amblyomma americanum). E. ewingii infections in dogs or ticks have been described in Missouri, Oklahoma, Tennessee, Arkansas, Texas, Florida, Georgia, Mississippi, North Carolina, and Virginia (143, 144). A. phagocytophilum is transmitted by the blacklegged tick
(I. scapularis) and is distributed in New England, North Central, and recently, Southeast United States, in addition to the Northeast of Mexico $(13,129)$. The western blacklegged tick (I. pacificus) is the principal vector in Northern California. In the US, the estimated average annual incidence of RMSF was 2.2 cases per million people. In Mexico, the incidence from 1975 to 1987 was 12.59 cases per 100,000 people in North and Northwest States. From 2009 to 2011 , there were 2616 reported cases with an incidence of 0.8 cases per 100,000 people. In 2012, there was an increase to 2875 cases in the States of Baja California and Coahuila in Northern Mexico. Due to the consistent increase and presence of this disease, Mexico started to officially report RMSF and other Rickettsial human cases in 2014 (145).

Ehrlichiosis was first recognized as a disease in the late 1980s, but did not become a reportable disease until 1999 in the US. The number of ehrlichiosis cases due to E. chaffeensis that have been reported to CDC has increased steadily since the disease became reportable, from 200 cases in 2000 to 961 cases in 2008 (138). The incidence increased from less than 1 to 2.5 cases per million people in 2000-2010. Both E. chaffeensis and E. ewingii are causes of human illness in the US, although the majority of reported cases identify E. chaffeensis as the causative agent of HME. HGA is more frequently reported than HME with an annual incidence of 1.6 cases per million during 2001-2002. In Mexico, the first Ehrlichiosis case was reported in 1999 (146). It is important to understand the involvement of dogs in the potential enzootic cycle for Ehrlichia infection acquired by humans in close contact with domestic dogs. In this sense, our research team found that human contact with Ehrlichia infected dogs have 14.9 times higher risk to become infected, and dogs infested with Ehrlichia infected ticks have 8.2 higher risk of being infected (128).

The understanding of vector-borne disease ecology has improved in recent years due to advancements in molecular biology, geographic information systems (GIS), and species distribution models (SDM) $(147,148)$. A recent study evaluated the presence of I. scapularis ticks in Texas and Northern Mexico, and forecasted the distribution of this tick species considering different climate change scenarios (13). It was observed that a geographic region could provide suitable environment where the competent vector for transmission of LD and other zoonotic pathogens would survive. The model presented in this study showed East Texas to include suitable habitat where established populations can exist (13), which agrees with findings from other studies (149). This model also showed expansion towards Central and to South Texas through a corridor along the Gulf Coast and Northern Mexico, forming a geographic continuum of habitat suitable for $I$. scapularis populations in the border region. Although no specific distribution model exists for I. scapularis in Mexico, a distribution model for the genus Ixodes generated with similar methodologies predicts a wide distribution covering Northeastern Mexico (132).

Variation in questing behaviors may significantly impact the type of hosts ticks encounter and may lead to differential host use within a particular study area (150). Therefore, further studies testing different sampling procedures, including different time of the day and season, would be needed to determine the phenology of I. scapularis in Southern US and Mexico and the questing behavior of the different developmental stages. These studies will 
be critical to determine how questing behavior will affect the risk for LD in humans and companion animals in the transboundary region.

\section{Leptospirosis}

Leptospirosis is a zoonotic infectious disease of worldwide distribution that is endemic in tropical and temperate climates, with higher prevalence in tropical countries (151-153). Leptospirosis can be caused by Leptospira interrogans, which in cludes 200 serovars affecting both domestic and wild mammals, and humans $(153,154)$. The reservoirs for these pathogens are wild or domestic animals such as rodents, cattle, or dogs (155). In urban areas, rodents (mostly rats) are the main carriers of the disease (156), whereas the dog is considered a dead-end host $(157,158)$. However, due to their close contact, dogs pose a risk of infection for human beings $(151,159)$. It has been suggested that ticks are potential vectors of Leptospira spp. (160).

In the forest region of Indiana, a study was conducted with 34 raccoons (Procyon lotor) to determine the presence of Leptospira. In this study, cell culture techniques, microscopic agglutination test (MAT), and PCR were used. The results indicated the presence of $L$. interrogans, L. kirschneri, and L. borgpetersen in raccoons from this region. For $L$. interrogans, the serovars most frequently detected were Bratislava (38.2\%) and Grippotyphosa (32.4\%). This finding indicated that L. interrogans is circulating in the raccoon population, which is acting as a reservoir for the pathogen. The racoon is an abundant species in the south Texas - northeast Mexico region.

Cervids may be involved in the epidemiology of leptospirosis. Diversified livestock production comprises activities aimed to breed in sustainable manner wild animals, including native and exotic species of deer. Ranches in northeast Mexico have been managed to be units for the conservation, management, and sustainable use of wildlife (UMA), which are dedicated to the diversification of livestock. A cross-sectional epidemiological study on leptospirosis was conducted with cervids at an UMA in Tamaulipas, Mexico (161). Of the 37 animals sampled, eighteen individuals were Axis deer (Cervus axis) and 19 Fallow deer (Cervus dama). Seropositivity for Leptospira spp. in all the cervids sampled was $13.5 \%$. Twenty-one percent of the Axis, and 5.5\% of the Fallow deer were seropositive. Positive deer were reactive to serovars Bratislava and Muenchen, which confirms the presence of this pathogen in deer in Northern Mexico (161). Similar seroepidemiological findings for leptospirosis in cervids have been reported in the US and Spain (162-165).

It is important to understand how global change may alter the pathogenic landscape of leptospirosis because this zoonosis is considered a major bacterial NTD in Texas and Mexico (11). For example, the water buffalo (Bubalus bubalis) is originally from Asia and was introduced in Mexico as an alternative livestock species during the 1990s (166). Water buffaloes produce milk, meat, and are used as working animals. Although subclinical Leptospira infection has been documented in other parts of the world and is considered a health risk to humans, information is lacking on the prevalence of leptospirosis in water buffalo herd in Mexico. An epidemiological cross-sectional study was conducted with a sample size of 368 blood specimens in the Mexican state of Veracruz to fill this knowledge gap. The overall sero-prevalence for Leptospirosis was
$53.5 \%$ (167). The most common serovars detected were Muenchen (44.3\%), Pyrogenes (11.4\%), Icterohaemorragiae (11.1\%), and Hardjo $(8.1 \%)$. In this study, the interaction between water buffaloes and dogs was identified to be a risk factor (167). This was the first study identifying seropositive buffaloes to L. interrogans and risk factors associated with Leptospirosis in Mexico (167).

Zoonoses common to pets threaten the health of humans, particularly children. A study conducted to determine the frequency of canine Leptospirosis in dogs from two shelters in the city of Veracruz, Mexico showed that 8.6\% (8/92) were seropositive. The most frequent serovar was Canicola (168). Similar results were observed in Yucatan, Mexico where the serovars present were Canicola and Icterohaemorrhagiae (169). Even though leptospirosis occurs in the transboundary region, more research is required to understand its epidemiology and mitigate the burden of this neglected zoonosis on human and domestic animal populations (11).

\section{Bartonellosis}

Bartonella species are fastidious gram-negative, facultative intracellular bacteria that cause host restricted hemotropic infections in mammals. Normally, they infect erythrocytes, macrophages, and endothelial cells. In addition, a number of Bartonella spp. are transmitted by blood sucking arthropods such as sand flies, biting flies, lice, and fleas. More recently, ticks and mites have been suggested as potential vectors for zoonotic Bartonella spp. (170-175). In addition, Bartonella spp. affect a number of mammals, including humans, dogs, horses, cattle, cats, and even marine animals $(176,177)$.

The number of Bartonella spp. identified infecting a wide range of mammalian species has significantly increased. Currently, a total of 13 species or subspecies can cause disease in humans, and most of them are zoonotic $(173,176,178)$. Bartonella henselae, the causative agent of cat-scratch disease (CSD) is the most recognized in the medical community together with B. quintana, the causative agent of Trench Fever, and B. bacilliformes, the causative agent of bacillary angiomatosis, Oroya fever and veruga peruana (176, 177). Moreover, most of the Bartonella species causing disease in humans and companion animals have a worldwide distribution, and are associated with poverty and overpopulation, as these bacteria thrive in crowded and unhygienic environments (172, 179-181). This aspect of B. quintana and B. elizabethae infections has been extensively reviewed elsewhere (180-184).

Cats have been classified as reservoirs for $B$. henselae, the causative agent of CSD, which is distributed worldwide. The prevalence of infection in felines is higher in warmer countries that it is in cold countries (178). In addition, cats tend to be bacteremic for months and in some instances for over a year (178). The cat flea (185), Ctenocephalides felis, is responsible for the transmission of the bacterial pathogen between cats. Studies by Finkelstein and collaborators (180) showed that $B$. henselae can remain viable in flea feces for over $72 \mathrm{~h}$. Therefore, transmission to humans can occur via inoculation of $B$. henselae from infected flea feces into the skin via open wounds, such a scratch lesion. The CDC documents over 20,000 CSD cases annually. Human cases have been reported in Texas (186-189), Mexico, and other Latin American countries $(190,191)$. Domestic dogs, together with wild canids, have been 
suggested as potential reservoirs for zoonotic Bartonella species, such as $B$. vinsonii subsp. berkhoffi, $B$. henselae, B. clarridgeiae, $B$. wahoensis, B. rochalimae, B. quintana, and B. elizabethae. In some cases, domestic dogs display a broad range of clinical signs $(174,176,178,192,193)$ similar to those observed in humans. Consequently, domestic dogs might be considered sentinels for Bartonella infections (178) as they are for other vector-borne infectious diseases (194-196).

The number of annual cases due to Bartonella infection in the US-Mexico transboundary region remains unknown even though more epidemiological information is available relative to bacterial NTD like leptospirosis (197). Bartonella infections are not reportable in humans or animals in the US and Mexico. This situation makes it difficult to understand the epidemiology and pathogenic landscape for Bartonellosis in a geographic region where about $17.6 \%$ of the population lives in poverty ${ }^{2}$.

\section{PROTOZOAN INFECTIOUS DISEASES Human babesiosis}

Human Babesiosis (HB) is caused by several species of apicomplexan tick-borne protozoa of the genus Babesia and is a zoonotic emerging disease globally although it is endemic in the US (198200). Surveillance for Babesiosis started in 2011 in 18 States. That year, there were 1,124 confirmed and probable human cases across the US (126). Most cases of naturally transmitted HB in the Northeastern and Midwestern US are caused by B. microti (201). Infection in other regions of the US and the world has been documented with Babesia species that remain to be fully characterized (202-204). In rural Mexico, human infection with Babesia spp. was documented during the 70 s (205), where $37 \%$ of the tested individuals were seropositive but asymptomatic, and all volunteers recalled having tick bites.

$\mathrm{HB}$ is a complex zoonotic disease system whose relevance as an emerging public health concern is considered to be the result of aspects related to global change $(206,207)$. Most zoonotic Babesia species are maintained in wildlife reservoirs, but gaps exist in our knowledge of several epidemiological aspects of $\mathrm{HB}$ in various parts of the world (208-210). The vector(s) and reservoir hosts of Babesia species affecting humans in Mexico and other Latin American countries remain unknown (211). Accurate diagnosis of HB in sub-tropical and tropical parts of Latin America can be complicated because of malaria-like symptoms in the case of affected patients (212), asymptomatic infection in others, and the possibility that tick bite may have resulted in co-infection with other tick-borne pathogens $(213,214)$ coupled with the use of serodiagnostic tools that cross-react with other Babesia and Plasmodium hemoparasites $(215,216)$. Thus, it is important to understand how environmental change (217), including the knowledge of vectors and reservoir hosts, could influence the patterns of zoonotic Babesia transmission at the regional level to evaluate the risk for the emergence of Babesiosis among humans in the South Texas-Northeast Mexico transboundary region.

Although its known geographic range appears to be expanding, it is possible that HB remains under-reported in the South Texas Northeast Mexico transboundary region (218-220). Increasing

${ }^{2}$ http://www.census.gov/hhes/www/poverty/data/incpovhlth/2012/tables.html evidence suggests that reservoir species and vectors are present in the Eastern sector of the border between the US and Mexico, and our knowledge of wildlife and domestic animals harboring Babesia species with the potential to be pathogenic to humans is expanding (204, 221, 222). The infection of cotton rats (Sigmodon hispidus) and raccoons (Procyon lotor) with B. microti presents a risk for HB in Northeast Florida (223). Both mammals are abundant in Texas and Northeast Mexico (129, 142,224,225). I. scapularis is the known vector in the Northeastern US and its presence has been documented in the US-Mexico transboundary region (13), but Clark et al. (223) suggested that additional Ixodes species might be transmitting B. microti in the Southeastern US, like the raccoon tick (I. texanus) and other Ixodes ticks known to feed on the cotton rat. I. texanus is distributed in Texas and Nuevo León (142, 226, 227). Of the ticks species present in the US and Mexico, which are known to infest the cotton rat $(13,228-230)$, D. variabilis and I. scapularis have been shown to harbor Babesia spp. and bite humans in Southern latitudes $(231,232)$. Suspected vectors of a Babesia detected in the woodrat (Neotoma micropus) with a partial $18 \mathrm{~S}$ rRNA sequence related to $B$. conradae included $A$. inornatum and $D$. variabilis, which are ticks reported to parasitize humans in Texas $(233,234)$. A. inornatum is found in the Mexican border States of Coahuila, Nuevo León, and Tamaulipas (142, 235). Blood donors from Texas were seropositive for B. duncani, but the vector and reservoir host species remain to be determined (236). Notably, four adult $A$. americanum and one adult $D$. variabilis $P C R$ positive for Babesia spp. were removed from humans in Texas (231). One of the $A$. americanum was infected with a large Babesia molecularly resembling a large Babesia detected in an immunocompromised dog residing in Texas (237). Nevertheless, the zoonotic potential of the other Babesia infecting A. americanum remains to be determined.

Global change is altering the distribution of ticks and tickborne diseases globally, and the South Texas-Northeast Mexico transboundary region is not immune to this process $(13,198$, 238). Environmental drivers for the emergence of $\mathrm{HB}$ as a public health concern in other parts of the world seem to be at play in the Texas-Mexico border $(219,231,232)$. Assessing the incidence of $\mathrm{HB}$ accurately requires knowledge of the rates for human-tick contact and infection in the vector population. However, $\mathrm{HB}$ is considered to be under-reported, even in states with a surveillance program and areas where the disease is known to be endemic (201). Diagnosis can be complicated because of co-infection with B. burgdorferi and Plasmodium spp. $(239,240)$. It remains to be determined if co-infection with B. burgdorferi and Babesia spp. affecting humans occurs in populations of $I$. scapularis inhabiting ecosystems spanning the US-Mexico border. However, the presence of potential vectors and reservoirs indicates that studies are required to determine if zoonotic Babesiosis is an unrecognized cause of illness among humans in that transboundary region. Tick-based surveillance has been proposed as an alternative approach to assess infection risk because it provides a more sensitive method for identifying areas where Babesiosis could be emerging, and could be used to estimate zoonotic prevalence in established areas (218). The adaptation of this strategy, with an international perspective and in the context of the One Health concept is suggested, as it was done recently for LD, to establish an 
early warning system for the emergence of HB in the Texas-Mexico border region $(13,241)$.

\section{Leishmaniasis}

Leishmaniasis is a vector-borne disease caused by Leishmania species of the family Kinetoplastidae, which is transmitted by sand flies of the genus Lutzomyia in the Americas and Phlebotomus in other regions of endemicity $(242,243)$. There are 98 countries where Leishmania is endemic, with the majority of cases occurring in developing nations (244). The distribution of competent vector species and leishmaniasis has expanded over the last decade as areas with suitable habitat for sand flies continue to increase due in part to shifts in climate (14). Of the 1.6 million new cases per year estimated to occur worldwide, approximately 600,000 are recorded (245). Moreover, leishmaniasis is estimated to affect about 12 million people in four continents (Africa, Americas, Asia, and Europe) $(245,246)$.

The leishmaniases have been divided in two main syndromes: Old World, and New World leishmaniasis (247). Old World leishmaniasis includes two clinical presentations: cutaneous leishmaniasis, which is confined to skin, and visceral leishmaniasis, which involves the bloodstream and inner organs. New World leishmaniasis' clinical presentation can manifest in a cutaneous form, or as a mucocutaneous syndrome, which involves mucous membranes in addition to the skin $(245,246)$. Presently, new terms are used to describe the clinical forms of leishmaniasis. The term mucosal leishmaniasis indicates the involvement of mucosal tissues such as mucous membranes of the upper respiratory tract and oral cavity, i.e. mucocutaneous leishmaniasis (246). Together with the cutaneous and diffuse cutaneous forms the mucocutaneous syndrome is one of the typical presentations of leishmaniasis in South America (248).

Twenty-one Leishmania species have been identified as human pathogens. They are systematically classified in four complexes. In the New World leishmaniasis is caused by species belonging to the subgenus Leishmania [such as Leishmania (Leishmania) mexicana, L. (Leishmania) amazonensis] and the subgenus Viannia [ $L$. (Viannia) braziliensis, L. (Viannia) panamensis, and L. (Viannia) guyanensis] $(246,249)$. In Mexico and US, cutaneous leishmaniasis is caused by a number of Leishmania spp. with widespread distributions and a variety of location-specific reservoir species (242). Numerous species causing cutaneous leishmaniasis have been identified in multiple mammalian species. L. mexicana is found from Central America to the Yucatan peninsula in Mexico, and cases have been reported in Texas (250). In the Old World, Leishmania major is a predominant cause of cutaneous Leishmaniasis.

In Mexico, the first clinically documented records of cutaneous leishmaniasis were from forested parts of the Yucatan Peninsula $(251,252)$. Until 1989, only eight cases of visceral leishmaniasis were reported; all of them were in the Balsas River basin, which includes the States of Guerrero, Puebla, Morelos, and Oaxaca (253). In Chiapas State, the first case was documented in Tuxtla Gutiérrez in 1990. An increase in cases in several municipalities was observed in subsequent years. From 1990 to 2006, 89 cases of American visceral leishmaniasis were reported in Chiapas State (254). In the US, human cases $(n=30)$ of non-travel-related (or autochthonous) disease have been reported since 1903 in the epidemic focus located in South-Central Texas. In 2008, nine cases of non-travel-related cutaneous leishmaniasis in Northern Texas, specifically in suburbs and smaller towns near the DallasFt. Worth metro area, were reported (255). Subsequently, four cases of autochthonous cutaneous Leishmaniasis were described in Northeastern Texas and Southeastern Oklahoma (256).

Several Leishmania species are transmitted zoonotically, and in the case of $L$. infantum, dogs are the main reservoir. In many settings, dogs may serve as a link between sylvatic and domestic cycles of visceral leishmaniasis. Dogs can cross forest-edge boundaries, thereby potentially bringing parasites to or from sylvatic systems and to and from other potential mammalian hosts (such as foxes, rodents, and opossums) (242). In Yucatan, Mexico, the prevalence of $L$. mexicana, $L$. infantum, and L. braziliensis in dog sera $(n=218)$ was $30.2,11.9$, and $8.2 \%$, respectively (257). Antibody based prevalence of $10.5 \%$ for L. mexicana and $11.57 \%$ for $L$. braziliensis has also been reported in cats (258). Vertical transmission of leshmaniasis has been characterized for dogs and people, causing an increased risk for infants born to parasitemic mothers (259). There have also been a number of non-travel-associated reports of cutaneous leishmaniasis in companion animals in Texas (250). Many of these cases of zoonotic cutaneous leishmaniasis were in cats, which may be associated with an outdoor life-style (250). Until recently, visceral leishmaniasis was thought to be primarily an imported disease in North America. Infected dogs had usually been imported from regions in Southern Europe or South America where L. infantum and L. chagasi were enzootic $(260,261)$. Additional risk factors for humans are related to their immunologic status and their ability to clear infection or maintain an asymptomatic state. These factors include concurrent infection with HIV, co-infections with helminthic parasites, drug abuse, and other immunosuppressive conditions (262).

A serosurvey conducted in the US looked at over 12,000 foxhounds and other canids, as well as 185 people in 35 States, to determine geographic extent, prevalence, host range, and modes of transmission. This study showed that foxhounds infected with Leishmania spp. were present in 18 States. However, no evidence of infection was found in humans (263). While companion animal infection and transmission occur, the predominant sylvatic reservoir in Texas is the Southern Plains woodrat, Neotoma micropus (264). Given the presence of sand fly vectors throughout the Southern US, it is possible that disease rates associated with $L$. mexicana infection will increase in the US due to climate change (14). South American species causing cutaneous leishmaniasis, including L. amazonensis, L. braziliensis, L. guyanensis, and L. panamensis, have sylvatic reservoirs (242). Thus, human risk factors for zoonotic cutaneous leishmaniasis are dependent upon exposure to vector species and the presence of reservoir species. Urbanization and wilderness encroachment have resulted in increased interactions between humans, reservoir, and vector species and the establishment of peri-urban domestic life cycles rather than sylvatic ones (242).

In Mexico, Lutzomyia olmeca olmeca, Lu. cruciata, Lu. shannoni, Lu. panamensis, and Lu. ylephiletor have been incriminated as vectors of Leishmania spp. $(14,265)$. In Northern Mexico and US, sand fly species suspected of being involved in Leishmania 
transmission to humans are Lu. diabolica and Lu. anthophora (266, 267). Lu. diabiolica is suspected of being a vector of L. mexicana and has been infected experimentally with L. infantum. In addition, $L u$. anthophora was able to transmit L. mexicana experimentally to mice $(268,269)$. Lu. shannoni is a possible vector of L. infantum, and is present in the Midwestern, Southern, and Southeastern US (263). The sand fly vectors of L. infantum causing visceral leishmaniasis in Mexico include Lu. longipalpis and Lu. evansi (270). Visceral leishmaniasis cases have been reported in the States of Chiapas, Guerrero, Puebal, Oaxaca, morelos, and Veracruz where dogs are considered to be disease reservoirs (270).

The pathogenic landscape for leishmaniasis in the transboundary region remains to be fully understood (271). In Mexico and the US, the risk for leishmaniasis has been associated with forest habitat like pluvial rainforest and agricultural fields close to the forest where reservoir mammals share habitat with humans. However, the incidence of leishmaniasis is increasing in domestic habitats as a direct consequence of the spreading of sand fly vectors to urbanized areas, especially the outskirts of cities (272). Moo-Llanes and collaborators (271) studied the current and future niche of North and Central American sand flies and concluded that continued landscape modification and future climate change will provide an increased opportunity for the geographic expansion of sand flies and increased risk for human exposure to Leishmania infection. The One Health paradigm could also be applied to enhance our ability to recognize Leishmania spp. in humans, domestic and wildlife reservoirs, and sand fly vectors in the US-Mexico transboundary region (273).

\section{Chagas}

Chagas is a zoonosis caused by Trypanosoma cruzi, a protozoan parasite that is present in a variety of mammalian reservoirs. This disease is one of the most prevalent parasitic diseases in the world (274) and kills around 45,000 people annually (275). The parasite is transmitted by species of insect vectors, commonly known as kissing bugs, belonging to the sub-family Triatominae in the family Reduviidae $(276,277)$. During the blood meal, the Triatomine kissing bug defecates and sheds the parasite in the feces. The parasite then enters its host through the bite wound or through contact with mucous membranes. The parasite can also be transmitted through blood transfusion, organ transplants, ingestion of infected food, or congenital transfusion (277). However, 85$96 \%$ of $T$. cruzi transmission to humans occurs via contact with infected feces from Triatomine insects (278). The acute phase of the disease is rarely recognized since cases are typically subclinical and asymptomatic. Chagas disease can then enter the chronic phase, in which $30 \%$ of cases will develop a fatal cardiomyopathy around 10-30 years post-infection (274, 279). Anti-parasitic treatment is mostly effective during the acute phase, and in infants and individuals up to 15 years old, although the currently accepted therapeutic options have limited efficacy and can have disabling side effects. Current research includes efforts to develop a vaccine for Chagas (11).

Chagas is endemic in the Southern US and Latin America, where it affects more than 10 million people (280) and it is spreading rapidly to non-endemic areas (276). It is considered a NTD in Texas (11), and Chagas could have been present in hunting-gatherer native Americans as far back as 1200 years ago, as described in a case of megacolon found in a mummified ancient resident of what is now known as Texas $(281,282)$. Studies conducted in US blood donors have demonstrated that T. cruzi seropositive donors have persistent infection with demonstrable parasitemia long after acquisition of infection (283). In Texas, for example, there are an estimated 267,000 people infected $(284,285)$. This is only an estimate based on small sero-prevalence studies and risk modeling. The exact risk for infection and the number of Chagas cases in Texas is unknown (277). In January 2013, Chagas became a reportable condition in Texas, which is a critical step toward documenting cases and understanding the epidemiology of this critical NTD.

There are several Chagas endemic areas in Mexico, including the States of Yucatán, Chiapas, Guerrero, Oaxaca, Jalisco, Veracruz, Puebla, Hidalgo, and Morelos where the disease occurs mainly in rural areas (286). The highest prevalence was observed in the Northeastern region of the country, which corresponds to the central area of a tropical region comprising the States of Hidalgo, San Luis Potosí, Veracruz, and the US neighbor State of Tamaulipas $(287,288)$. Recent cases of Chagas have been reported in Coahuila $(289,290)$ where T. cruzi infection has been found also in blood donors (290). There have been new records of T. gerstaeckeri and T. rubida in Nuevo Leon and Coahuila (291). As in the US, T. cruzi is increasingly transmitted through blood transfusions partly due to migration from rural areas toward Mexico City (292). More than 180 domestic, synanthropic, and wild species of mammals, especially rodents and marsupials, are likely to be infected with T. cruzi and to be involved in the disease transmission cycle (293). In the Yucatan peninsula, the anti-T. cruzi antibody prevalence in dogs and cats were determined to be 14.76 and $4.21 \%$, respectively $(258,294)$. In addition, an active canine $T$. cruzi transmission cycle with severe symptoms affecting a broad range of dog breeds and age groups was observed in several counties in Texas (295). Further, in regions of Central Mexico, studies have demonstrated that canine sero-prevalence is directly correlated to human sero-prevalence, demonstrating the importance of this host as a sentinel species (296). Serosurveillance in shelter dogs was found useful as a public health tool to assess the risk for T. cruzi infection (297).

Currently, 40 species of triatomine insects are known to be naturally infected with T. cruzi in North America. Twenty-eight species are found exclusively in Mexico, and eight are shared with the US (298). Considering the vectorial transmission capacity and widespread distribution in Mexico, important species include Triatoma barberi, T. dimidiata, T. phyllosoma, T. longipennis, T. mazzottii, T. pallidipennis, T. picturata, T. mexicana, and T. gerstaeckeri $(299,300)$. T. gerstaeckeri and T. sanguisuga are the most common triatomine species in the Southern US and might be involved in T. cruzi transmission. Different reports have revealed information about the major vectors in endemic areas of Mexico (287). In the State of Veracruz, the main recognized vectors are $T$. dimidiata and $R$. prolixus, and three vector species, $P$. rufotuberculatus, $R$ prolixus, and $T$. dimidiata, have been identified in the State of Chiapas. Two important vectors in the Southern region of the State of Mexico are T. pallidipennis (97.4\%) and T. dimidiata $(2.6 \%)$, and $28.0 \%$ of the triatomines in that region were infected 
with T. cruzi (299). Studies conducted in rural communities of Yucatan, Mexico found that $21.9 \%$ of T. dimidiata (23.9\% of adults and $13 \%$ of nymphs) were infected with T. cruzi (301).

An accepted strategy to control and prevent Chagas disease is through the management of triatomine insect infestations in domestic areas based on government and population surveillance programs (302). These programs have been successful in South America, including Mexico. However, a surveillance program aimed at controlling triatomine vectors and preventing Chagas disease has not been attempted in the US, perhaps due to the lack of data on human cases and vector-parasite distribution. Triatomine insects can be found in domestic and sylvatic life cycles, which could make efforts to control insect infestations difficult in domestic habitats due to the continuity of insect populations (303).

Recent models of risk assessment have identified Hidalgo and Cameron counties as the areas of highest risk for human infection of Chagas disease in Texas (277). Hidalgo County has suitable climatic conditions for the vector (304). This risk factor could be compounded by a high poverty rate among the border population and substandard housing. In Hidalgo County alone, almost 130,000 people live in unincorporated residential areas known as colonias. Much of this population is characterized by low incomes ( $<\$ 10,000$ per year) and poorly constructed residences with substandard sanitation and drainage systems, which are landscape characteristics that provide suitable habitat for Triatomine insects $(11,277)$. Hidalgo and Cameron County form part of the Lower Rio Grande Valley (LRGV), one of the main points of entry for immigrants from Latin America, mainly Mexico. Since Chagas disease is endemic to tropical areas, it is possible that migrants can carry the disease into the US via the LRGV (11). Because Chagas became a reportable disease in Texas in 2013, it can be argued that sufficient epidemiologic data are lacking to implement a scientifically sound disease control and prevention program yet. To be effective, a management program to control and prevent Chagas disease in south Texas will probably need to be combined with government and population-based surveillance of insect infestation. Important challenges to overcome include a lack of knowledge among the local population about Chagas disease and how to identify insect vectors.

Climate change could drive enhanced transmission of T. cruzi (12). A potential Northern shift from current range due to climate change could occur with two of the most common triatomine $T$. cruzi vectors in the Southern US (T. gerstaeckeri and T. sanguisuga). Furthermore, an increase in temperature may have influenced the behavior of triatomine species $(305,306)$. When temperature exceeds $30^{\circ} \mathrm{C}$ and humidity is low, the insects increase their feeding rate to avoid dehydration. In addition, in domestic life cycles, when indoor temperatures increase, the insects may develop shorter life cycles and reach higher population densities (305). High temperatures could also speed up the development of $T$. cruzi in vectors (307).

Trypanosoma cruzi has three infective forms capable of infecting its host and currently six DTUs (discrete typing units) are recognized in the taxon. These DTUs correlate with mammalian hosts specific interactions in distinct time-space scales. We know relatively little about confirmed mammalian T. cruzi hosts in the
US. More studies are needed to produce a comprehensive list of confirmed T. cruzi hosts as well as time-space scales for the operative interactions of hosts, vectors, and parasites. To better understand the epidemiology of Chagas disease in the TexasMexico transboundary region, ongoing research could focus on detecting T. cruzi infection status of vectors, potential role of the different reservoirs and hosts in the parasite cycles, and DTUs identification (12).

\section{CONCLUDING REMARKS}

The threat of zoonotic diseases to human and animal populations in the Mexico-US border along the Rio Grande is documented here. Attention is called to a gap in understanding of the pathogenic landscape for zoonotic vector-borne diseases in this transboundary region. Among other things, research on ecosystem processes, land use, and human behaviors is required because the region analyzed functions as a pathway for the movement of humans and animal migrations, and thus links Central America/Mexico with the US and Canada. The One Health approach for international collaboration on veterinary and public health research is proposed to generate the knowledge base that can translate into strategies to mitigate the risk of zoonotic diseases in the US-Mexico border.

\section{ACKNOWLEDGMENTS}

Maria Dolores Esteve-Gassent has obtained support for this study through the Department of Veterinary Pathobiology, Texas A\&M University, AgriLife grant TEXV 6579 (Project I-9524), the AgriLife-TVMDL seed grant to the project entitled "Improving diagnostic methods for Lyme disease, and epidemiology of human and animal infections in TX" and the bi-national cooperative grant TAMU-CONACYT-052 "Typing virulent isolates of Lyme disease agents in Central Mexico.” Ivan Castro-Arellano received a Research Enhancement Program Grant from Texas State University. Teresa P. Feria-Arroyo and Ramiro Patino are supported by an NIH grant 5R25GM100866-02 awarded to Robert K. Dearth and Jason G. Parsons at The University of Texas-Pan American. Jose Guillermo Estrada-Franco has been supported by grants from SEP/PROMEP/103.5/12/9839, UAEM (PTC-259) and

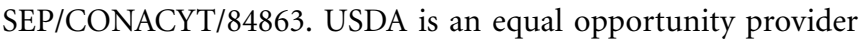
and employer.

\section{SUPPLEMENTARY MATERIAL}

The Supplementary Material for this article can be found online at http://www.frontiersin.org/Journal/10.3389/fpubh.2014. 00177/abstract

\section{REFERENCES}

1. EPA-SEMARNAT. Border 2020: U.S.-Mexico Environmental Program. Washington, DC: U.S.-Mexico Border Health Commission EPA (2013).

2. Sleeter BM, Wilson TS, Acevedo W. Status and Trends of Land Change in the Western United States - 1973 to 2000. Washington, DC: U.S. Geological Survey Professional Paper 1794-A (2012). 324 p.

3. Relman DA, Choffnes ER, Mack A. Infectious Disease Movement in a Borderless World: Workshop Summary. Washington, DC: The National Academies Press (2010).

4. Garza Ramos J. Current situation of the most frequent zoonosis in Mexico. Gac Med Mex (2010) 146(6):430-6. 
5. Medrano C, Boadella M, Barrios H, Cantu A, Garcia Z, de la Fuente J, et al. Zoonotic pathogens among white-tailed deer, Northern Mexico, 2004-2009. Emerg Infect Dis (2012) 18(8):1372-4. doi:10.3201/eid1808.111902

6. Kjemtrup AM, Conrad PA. Human babesiosis: an emerging tick-borne disease. Int J Parasitol (2000) 30(12-13):1323-37. doi:10.1016/S0020-7519(00) 00137-5

7. Paddock CD, Yabsley MJ. Ecological havoc, the rise of white-tailed deer, and the emergence of Amblyomma americanum-associated zoonoses in the United States. Curr Top Microbiol Immunol (2007) 315:289-324. doi:10.1007/978-3540-70962-6_12

8. Kena G, Aud S, Johnson F, Wang X, Zhang J, Rathbun A, et al. The Condition of Education, 2014. Washington, DC: U.S. Department of Education (2014).

9. Nawrotzki RJ, Riosmena F, Hunter LM. Do rainfall deficits predict U.S.-bound migration from rural Mexico? Evidence from the Mexican census. Popul Res Policy Rev (2013) 32(1):129-58. doi:10.1007/s11113-012-9251-8

10. Boano C. FMO Research Guide on Climate Change and Displacement. Forced Migration Report No.: fmo046 (2008). Available from: http://www. forcedmigration.org/guides/fmo046/

11. Hotez PJ, Bottazzi ME, Dumonteil E, Valenzuela JG, Kamhawi S, Ortega J, et al. Texas and Mexico: sharing a legacy of poverty and neglected tropical diseases. PLoS Negl Trop Dis (2012) 6(3):e1497. doi:10.1371/journal.pntd.0001497

12. Garza M, Feria Arroyo TP, Casillas EA, Sanchez-Cordero V, Rivaldi CL, Sarkar S. Projected future distributions of vectors of Trypanosoma cruzi in North America under climate change scenarios. PLoS Negl Trop Dis (2014) 8(5):e2818 doi:10.1371/journal.pntd.0002818

13. Feria-Arroyo TP, Castro-Arellano I, Gordillo-Perez G, Cavazos AL, VargasSandoval M, Grover A, et al. Implications of climate change on distribution of tick vector Ixodes scapularis and risk for Lyme disease in Texas-Mexico transboundary region. Parasit Vectors (2014) 7(1):199. doi:10.1186/17563305-7-199

14. Gonzalez C, Wang O, Strutz SE, Gonzalez-Salazar C, Sanchez-Cordero V, Sarkar S. Climate change and risk of leishmaniasis in North America: predictions from ecological niche models of vector and reservoir species. PLoS Negl Trop Dis (2010) 4(1):e585. doi:10.1371/journal.pntd.0000585

15. Greer A, Ng V, Fisman D. Climate change and infectious diseases in North America: the road ahead. CMAJ (2008) 178(6):715-22. doi:10.1503/cmaj. 081325

16. Melillo JM, Richmond TT, Yohe GW. Climate change impacts in the United States: the third national climate assessment. Program USGCR. Washington, DC: U.S. Government Printing Office (2014). 841 p.

17. Jones KE, Patel NG, Levy MA, Storeygard A, Balk D, Gittleman JL, et al. Global trends in emerging infectious diseases. Nature (2008) 451(7181):990-3. doi:10.1038/nature06536

18. Lambin EF, Tran A, Vanwambeke SO, Linard C, Soti V. Pathogenic landscapes: interactions between land, people, disease vectors, and their animal hosts. Int J Health Geogr (2010) 9:54. doi:10.1186/1476-072x-9-54

19. Shuman EK. Global climate change and infectious diseases. Int J Occup Environ Med (2011) 2(1):11-9.

20. Beugnet F, Chalvet-Monfray K. Impact of climate change in the epidemiology of vector-borne diseases in domestic carnivores. Comp Immunol Microbiol Infect Dis (2013) 36(6):559-66. doi:10.1016/j.cimid.2013.07.003

21. Patz JA, Olson SH. Climate change and health: global to local influences on disease risk. Ann Trop Med Parasitol (2006) 100(5-6):535-49. doi:10.1179/ 136485906 X97426

22. IPCC. Summary for Policymakers. In: Solomon S, Quin D, Manning M, Chen Z, Marquis M, Averyt KB, et al, editors. In Climate Change 2007: The Physical Sciences Basis. Contribution of Working Group I to Fourth Assessment Report of the Intergovernmental Panel on Climate Change. Cambridge: Cambridge University Press (2007).

23. Githeko AK, Lindsay SW, Confalonieri UE, Patz JA. Climate change and vector-borne diseases: a regional analysis. Bull World Health Organ (2000) 78(9):1136-47.

24. Gubler DJ, Reiter P, Ebi KL, Yap W, Nasci R, Patz JA. Climate variability and change in the United States: potential impacts on vector- and rodent-borne diseases. Environ Health Perspect (2001) 109(Suppl 2):223-33. doi:10.2307/ 3435012

25. Hunter PR. Climate change and waterborne and vector-borne disease. J Appl Microbiol (2003) 94:37S-46S. doi:10.1046/j.1365-2672.94.s1.5.x
26. Harrus S, Baneth G. Drivers for the emergence and re-emergence of vector-borne protozoal and bacterial diseases. Int J Parasitol (2005) 35(1112):1309-18. doi:10.1016/j.ijpara.2005.06.005

27. Hurtado-Diaz M, Riojas-Rodriguez H, Rothenberg SJ, Gomez-Dantes H, Cifuentes E. Impact of climate variability on the incidence of dengue in Mexico. Trop Med Int Health (2007) 12(11):1327-37. doi:10.1111/j.1365-3156.2007. 01930.x

28. Trevejo RT, Rigau-Perez JG, Ashford DA, McClure EM, Jarquin-Gonzalez C, Amador JJ, et al. Epidemic leptospirosis associated with pulmonary hemorrhage-Nicaragua, 1995. JInfect Dis (1998) 178(5):1457-63. doi:10.1086/ 314424

29. Carbajo AE, Vera C, Gonzalez PL. Hantavirus reservoir Oligoryzomys longicaudatus spatial distribution sensitivity to climate change scenarios in Argentine Patagonia. Int J Health Geogr (2009) 8:44. doi:10.1186/1476-072X-8-44

30. Hotez PJ, Dumonteil E, Woc-Colburn L, Serpa JA, Bezek S, Edwards MS, et al. Chagas disease: "the new HIV/AIDS of the Americas." PLoS Negl Trop Dis (2012) 6(5):e1498. doi:10.1371/journal.pntd.0001498

31. Mack RN, Smith MC. Invasive plants as catalysts for the spread of human parasites. NeoBiota (2011) 9:13-29. doi:10.3897/neobiota.9.1156

32. Williams SC, Ward JS, Worthley TE, Stafford KC. Managing Japanese barberry (Ranunculales: Berberidaceae) infestations reduces blacklegged tick (Acari: Ixodidae) abundance and infection prevalence with Borrelia burgdorferi (Spirochaetales: Spirochaetaceae). Environ Entomol (2009) 38:977-84. doi:10.1603/022.038.0404

33. Williams SC, Ward JS. Effects of Japanese barberry (Ranunculales: Berberidaceae) removal and resulting microclimatic changes on Ixodes scapularis (Acari: Ixodidae) abundances in Connecticut, USA. Environ Entomol (2010) 39:1911-21. doi:10.1603/EN10131

34. Varma M. In: Service MW, editor. The Encyclopedia of Arthropod-Transmitted Infections of Man and Domesticated Animals. Wallingford: CABI Publishing (2001). p. 254-60.

35. Nava S, Mastropaolo M, Guglielmone AA, Mangold AJ. Effect of deforestation and introduction of exotic grasses as livestock forage on the population dynamics of the cattle tick Rhipicephalus (Boophilus) microplus (Acari: Ixodidae) in Northern Argentina. Res Vet Sci (2013) 95(3):1046-54. doi:10.1016/J. Rvsc.2013.09.013

36. Yang CH, Everitt JH, Goolsby JA. Mapping Giant Reed (Arundo donax) infestations along the Texas-Mexico portion of the Rio Grande with aerial photography. Invasive Plant Sci Manag (2011) 4(4):402-10. doi:10.1614/Ipsm-D-1000081.1

37. Racelis AE, Davey RB, Goolsby JA, De Leon AA, Varner K, Duhaime R. Facilitative ecological interactions between invasive species: Arundo donax stands as favorable habitat for cattle ticks (Acari: Ixodidae) along the US-Mexico border. J Med Entomol (2012) 49(2):410-7. doi:10.1603/Me11104

38. Samish M, Alekseev E. Arthropods as predators of ticks (Ixodoidea). J Med Entomol (2001) 38(1):1-11. doi:10.1603/0022-2585-38.1.1

39. Fleetwood SC, Teel PD, Thompson G. Impact of imported fire ant hymenoptera, Formicidae on lone star tick Acari, Ixodidae mortality in open and canopied pasture aabitats of East Central Texas. Southwest Entomol (1984) 9(2):158-63.

40. Jemal A, Hughesjones M. A review of the red imported fire ant (Solenopsis invicta Buren) and its impacts on plant, animal, and human health. Prev Vet Med (1993) 17(1-2):19-32. doi:10.1016/0167-5877(93)90051-T

41. Graybill HW. Studies on the biology of the Texas-fever tick. In: USDA, Bureau of Animal Industry. Bulletin No. 130 (1991). p. 42.

42. Sutherst RW. Variation in the numbers of the cattle tick, Boophilus microplus (Canestrini), in a moist habitat made marginal by low-temperatures. J Aust Entomol Soc (1983) 22:1-5. doi:10.1111/j.1440-6055.1983.tb01828.x

43. Sutherst RW, Sutherland ID, Bourne AS, Maywald GF, Stegeman DA. Ecology of the cattle tick (Boophilus microplus) in sub-tropical Australia. 1. Introduction and Free-Living Stages. Aust J Agric Res (1988) 39(2):285-97. doi:10.1071/Ar9880285

44. Davey RB, Cooksey LM, Despins JL. Survival of larvae of Boophilus annulatus, Boophilus microplus, and Boophilus hybrids (Acari, Ixodidae) in different temperature and humidity regimes in the laboratory. Vet Parasitol (1991) 40(34):305-13. doi:10.1016/0304-4017(91)90110-H

45. Urdaz-Rodriguez J, Fosgate G, Alleman AR, Rae O, Donovan A, Binford $\mathrm{M}$, et al. Association between ecological factors and the presence of 
Rhipicephalus (Boophilus) microplus larvae in Puerto Rico. Exp Appl Acarol (2012) 58(2):145-57. doi:10.1007/S10493-012-9573-6

46. Calisher CH, Karabatsos N. Arbovirus serogroups: definition and geographic distribution. In: Monath TP, editor. The Arboviruses: Epidemiology and Ecology (Vol. 1), Boca Raton, FL: CRC Press (1988). p. 19-57.

47. Weaver SC, Ferro C, Barrera R, Boshell J, Navarro JC. Venezuelan equine encephalitis. Annu Rev Entomol (2004) 49:141-74. doi:10.1146/annurev.ento. 49.061802.123422

48. Aguilar PV, Estrada-Franco JG, Navarro-Lopez R, Ferro C, Haddow AD, Weaver SC. Endemic Venezuelan equine encephalitis in the Americas: hidden under the dengue umbrella. Future Virol (2011) 6(6):721-40. doi:10.2217/FVL.11.5

49. Johnson KM, Martin DH. Venezuelan equine encephalitis. Adv Vet Sci Comp Med (1974) 18(0):79-116.

50. Walton TE, Grayson MA. Venezuelan equine encephalomyelitis. In: Monath TP, editor. The Arboviruses: Epidemiology and Ecology (Vol. 4), Boca Raton, FL: CRC Press (1988). p. 203-31.

51. Albornoz JE. La peste loca de las bestias (Enfermedad de Borna). Colombia. Min Agr Com (1935) 127(1):75-9.

52. Kubes V, Ríos FA. The causative agent of infectious equine encephalomyelitis in Venezuela. Science (1939) 90(2323):20-1. doi:10.1126/science.90.2323.20

53. Beck CE, Wyckoff RW. Venezuelan equine encephalomyelitis. Science (1938) 88(2292):530. doi:10.1126/science.88.2292.530

54. APHISU. Origin and Spread of Venezuelan Equine Encephalomylitis. Hyattsville, MD: USDA Animal Health and Inspection Service (APHIS), Veterinary Services (1973).

55. Sanmartin-Barberi C, Groot H, Osorno-Mesa E. Human epidemic in Colombia caused by the Venezuelan equine encephalomyelitis virus. Am J Trop Med Hyg (1954) 3(2):283-93.

56. Lord RD. History and geographic distribution of Venezuelan equine encephalitis. Bull Pan Am Health Organ (1974) 8(2):100-10.

57. Weaver SC, Bellew LA, Rico-Hesse R. Phylogenetic analysis of alphaviruses in the Venezuelan equine encephalitis complex and identification of the source of epizootic viruses. Virology (1992) 191(1):282-90.

58. Rico-Hesse R, Weaver SC, de Siger J, Medina G, Salas RA. Emergence of a new epidemic/epizootic Venezuelan equine encephalitis virus in South America. Proc Natl Acad Sci U S A (1995) 92(12):5278-81. doi:10.1073/pnas. 92.12.5278

59. Oberste MS, Fraire M, Navarro R, Zepeda C, Zarate ML, Ludwig GV, et al. Association of Venezuelan equine encephalitis virus subtype IE with two equine epizootics in Mexico. Am J Trop Med Hyg (1998) 59(1):100-7.

60. Rivas F, Diaz LA, Cardenas VM, Daza E, Bruzon L, Alcala A, et al. Epidemic Venezuelan equine encephalitis in La Guajira, Colombia, 1995. J Infect Dis (1997) 175(4):828-32.

61. Weaver SC, Salas R, Rico-Hesse R, Ludwig GV, Oberste MS, Boshell J, et al. Reemergence of epidemic Venezuelan equine encephalomyelitis in South America. VEE Study Group. Lancet (1996) 348(9025):436-40.

62. Morilla-Gonzales A, deMucha-Macias J. Estudio de una epizootia de encefalitis equina de Venezuela ocurrida en Tamaulipas, Mexico. Rev Invest Salud Publica (1969) 29:3-20.

63. Sudia WD, Fernandez L, Newhouse VF, Sanz R, Calisher CH. Arbovirus vector ecology studies in Mexico during the 1972 Venezuelan equine encephalitis outbreak. Am J Epidemiol (1975) 101(1):51-8.

64. Reta G. Equine Disease: Mexico. Washington, DC: Pan American Health Organization (1972). p. 209-11.

65. Grayson MA, Galindo P. Ecology of Venezuelan equine encephalitis virus in Panama. J Am Vet Med Assoc (1969) 155(12):2141-5.

66. Oberste MS, Schmura SM, Weaver SC, Smith JF. Geographic distribution of Venezuelan equine encephalitis virus subtype IE genotypes in Central America and Mexico. Am J Trop Med Hyg (1999) 60(4):630-4.

67. Estrada-Franco JG, Navarro-Lopez R, Freier JE, Cordova D, Clements T, Moncayo A, et al. Venezuelan equine encephalitis virus, Southern Mexico. Emerg Infect Dis (2004) 10(12):2113-21. doi:10.3201/eid1012.040393

68. Rico-Hesse R, Roehrig JT, Dickerman RW. Monoclonal antibodies define antigenic variation in the ID variety of Venezuelan equine encephalitis virus. Am J Trop Med Hyg (1988) 38(1):187-94.

69. Dietz WH Jr, Alvarez O Jr, Martin DH, Walton TE, Ackerman LJ, Johnson KM. Enzootic and epizootic Venezuelan equine encephalomyelitis virus in horses infected by peripheral and intrathecal routes. J Infect Dis (1978) 137(3):227-37. doi:10.1093/infdis/137.3.227
70. Martin DH, Dietz WH, Alvaerez O Jr, Johnson KM. Epidemiological significance of Venezuelan equine encephalomyelitis virus in vitro markers. Am J Trop Med Hyg (1982) 31(3 Pt 1):561-8.

71. Walton TE, Alvarez O Jr, Buckwalter RM, Johnson KM. Experimental infection of horses with an attenuated Venezuelan equine encephalomyelitis vaccine (strain TC-83). Infect Immun (1972) 5(5):750-6.

72. Brault AC, Powers AM, Ortiz D, Estrada-Franco JG, Navarro-Lopez R, Weaver SC. Venezuelan equine encephalitis emergence: enhanced vector infection from a single amino acid substitution in the envelope glycoprotein. Proc Natl Acad Sci U S A (2004) 101(31):11344-9. doi:10.1073/pnas.0402905101

73. Adams AP, Navarro-Lopez R, Ramirez-Aguilar FJ, Lopez-Gonzalez I, Leal G, Flores-Mayorga JM, et al. Venezuelan equine encephalitis virus activity in the Gulf Coast region of Mexico, 2003-2010. PLoS Negl Trop Dis (2012) 6(11):e1875. doi:10.1371/journal.pntd.0001875

74. Cupp EW, Scherer WF, Lok JB, Brenner RJ, Dziem GM, Ordonez JV. Entomological studies at an enzootic Venezuelan equine encephalitis virus focus in Guatemala, 1977-1980. Am J Trop Med Hyg (1986) 35(4):851-9.

75. Scherer WF, Dickerman RW. Ecologic studies of Venezuelan encephalitis virus in Southeastern Mexico. 8. Correlations and conclusions. Am J Trop Med Hyg (1972) 21(2):86-9.

76. Cupp EW, Scherer WF, Ordonez JV. Transmission of Venezuelan encephalitis virus by naturally infected Culex (Melanoconion) opisthopus. Am J Trop Med Hyg (1979) 28(6):1060-3.

77. Deardorff ER, Estrada-Franco JG, Freier JE, Navarro-Lopez R, Travassos Da Rosa A, Tesh RB, et al. Candidate vectors and rodent hosts of Venezuelan equine encephalitis virus, Chiapas, 2006-2007. Am J Trop Med Hyg (2011) 85(6):1146-53. doi:10.4269/ajtmh.2011.11-0094

78. Sudia WD, McLean RG, Newhouse VF, Johnston JG, Miller DL, Trevino H, et al. Epidemic Venezuelan equine encephalitis in North America in 1971: vertebrate field studies. Am J Epidemiol (1975) 101(1):36-50.

79. Suarez OM, Bergold GH. Investigations of an outbreak of Venezuelan equine encephalitis in towns of Eastern Venezuela. Am J Trop Med Hyg (1968) 17(6):875-80.

80. Anyamba A, Linthicum KJ, Small JL, Collins KM, Tucker CJ, Pak EW, et al. Climate teleconnections and recent patterns of human and animal disease outbreaks. PLoS Negl Trop Dis (2012) 6:e1465. doi:10.1371/journal.pntd.0001465

81. Jonsson CB, Figueiredo LT, Vapalahti O. A global perspective on hantavirus ecology, epidemiology, and disease. Clin Microbiol Rev (2010) 23(2):412-41. doi:10.1128/CMR.00062-09

82. Hjelle B, Torres-Perez F. Hantaviruses in the Americas and their role as emerging pathogens. Viruses (2010) 2(12):2559-86. doi:10.3390/v2122559

83. Montoya-Ruiz C, Diaz FJ, Rodas JD. Recent evidence of hantavirus circulation in the American tropic. Viruses (2014) 6(3):1274-93. doi:10.3390/v6031274

84. Plyusnin A, Morzunov SP. Virus evolution and genetic diversity of Hantaviruses and their rodent hosts. Curr Top Microbiol Immunol (2001) 256:47-75. doi:10.1007/978-3-642-56753-7_4

85. Plyusnin A, Sironen T. Evolution of Hantaviruses: co-speciation with reservoir hosts for more than 100MYR. Virus Res (2014) 187:22-6. doi:10.1016/j. virusres.2014.01.008

86. Sánchez-Cordero V, Peterson AT, Martínez-Meyer E, Rita F. Distribución de roedores reservorios del virus causante del síndrome pulmonar por hantavirus y regiones de posible riesgo en México. Acta Zool Mex (2005) 21(3):79-91.

87. Milazzo ML, Cajimat MN, Hanson JD, Bradley RD, Quintana M, Sherman C, et al. Catacamas virus, a hantaviral species naturally associated with Oryzomys couesi (Coues' oryzomys) in Honduras. Am J Trop Med Hyg (2006) 75(5):1003-10.

88. Milazzo ML, Cajimat MN, Romo HE, Estrada-Franco JG, Iniguez-Davalos LI, Bradley RD, et al. Geographic distribution of Hantaviruses associated with neotomine and sigmodontine rodents, Mexico. Emerg Infect Dis (2012) 18(4):571-6. doi:10.3201/eid1804.111028

89. Schmaljohn C, Hjelle B. Hantaviruses: a global disease problem. Emerg Infect Dis (1997) 3(2):95-104. doi:10.3201/eid0302.970202

90. Ceballos G, Oliva G. Los Mamíferos Silvestres de México. México: Distrito Federal (2005).

91. Schmidly D. The Mammals of Texas: Revised Edition. Austin, TX: University of Texas Press (2004).

92. Castro-Arellano I, Suzan G, Leon RF, Jimenez RM, Lacher TE Jr. Survey for antibody to Hantaviruses in Tamaulipas, Mexico. J Wildl Dis (2009) 45(1):207-12. doi:10.7589/0090-3558-45.1.207 
93. Gonzalez-Padron S. Diversidad y Abundancia de Roedores Reservorios de Hantavirus en un Gradient de Impacto Antropogenico en Mexico. Mexico: Universidad Nacional Autonoma de Mexico (2014).

94. Mantooth SJ, Milazzo ML, Bradley RD, Hice CL, Ceballos G, Tesh RB, et al. Geographical distribution of rodent-associated Hantaviruses in Texas. J Vector Ecol (2001) 26(1):7-14.

95. Rivers MN, Alexander JL, Rohde RE, Pierce JR Jr. Hantavirus pulmonary syndrome in Texas: 1993-2006. South Med J (2009) 102(1):36-41. doi:10.1097/ SMJ.0b013e318187d06f

96. Baneth G. Tick-borne infections of animals and humans: a common ground. Int J Parasitol (2014) 44(9):591-6. doi:10.1016/j.ijpara.2014.03.011

97. Parola P, Raoult D. Ticks and tickborne bacterial diseases in humans: an emerging infectious threat. Clin Infect Dis (2001) 32(6):897-928. doi:10.1086/319347

98. Stanek G, Reiter M. The expanding Lyme Borrelia complex - clinical significance of genomic species? Clin Microbiol Infect (2011) 17(4):487-93. doi:10.1111/j.1469-0691.2011.03492.x

99. Stanek G, Wormser GP, Gray J, Strle F. Lyme borreliosis. Lancet (2012) 379(9814):461-73. doi:10.1016/S0140-6736(11)60103-7

100. Margos G, Vollmer SA, Ogden NH, Fish D. Population genetics, taxonomy, phylogeny and evolution of Borrelia burgdorferi sensu lato. Infect Genet Evol (2011) 11(7):1545-63. doi:10.1016/j.meegid.2011.07.022

101. Rudenko N, Golovchenko M, Grubhoffer L, Oliver JH Jr. Updates on Borrelia burgdorferi sensu lato complex with respect to public health. Ticks Tick Borne Dis (2011) 2(3):123-8. doi:10.1016/j.ttbdis.2011.04.002

102. Mannelli A, Bertolotti L, Gern L, Gray J. Ecology of Borrelia burgdorferi sensu lato in Europe: transmission dynamics in multi-host systems, influence of molecular processes and effects of climate change. FEMS Microbiol Rev (2012) 36(4):837-61. doi:10.1111/j.1574-6976.2011.00312.x

103. Radolf JD, Caimano MJ, Stevenson B, Hu LT. Of ticks, mice and men: understanding the dual-host lifestyle of Lyme disease spirochaetes. Nat Rev Microbiol (2012) 10(2):87-99. doi:10.1038/nrmicro2714

104. Jaulhac B, Heller R, Limbach FX, Hansmann Y, Lipsker D, Monteil H, et al. Direct molecular typing of Borrelia burgdorferi sensu lato species in synovial samples from patients with Lyme arthritis. J Clin Microbiol (2000) 38(5):1895-900.

105. Williamson PC, Billingsley PM, Teltow GJ, Seals JP, Turnbough MA, Atkinson SF. Borrelia, Ehrlichia, and Rickettsia spp. in ticks removed from persons, Texas, USA. Emerg Infect Dis (2010) 16(3):441-6. doi:10.3201/eid1603.091333

106. LoGiudice K, Duerr ST, Newhouse MJ, Schmidt KA, Killilea ME, Ostfeld RS. Impact of host community composition on Lyme disease risk. Ecology (2008) 89(10):2841-9. doi:10.1890/07-1047.1

107. LoGiudice K, Ostfeld RS, Schmidt KA, Keesing F. The ecology of infectious disease: effects of host diversity and community composition on Lyme disease risk. Proc Natl Acad Sci U S A (2003) 100(2):567-71. doi:10.1073/pnas. 0233733100

108. Bunikis J, Garpmo U, Tsao J, Berglund J, Fish D, Barbour AG. Sequence typing reveals extensive strain diversity of the Lyme borreliosis agents Borrelia burgdorferi in North America and Borrelia afzelii in Europe. Microbiology (2004) 150(Pt 6):1741-55. doi:10.1099/mic.0.26944-0

109. Ogden NH, Tsao JI. Biodiversity and Lyme disease: dilution or amplification? Epidemics (2009) 1(3):196-206. doi:10.1016/j.epidem.2009.06.002

110. Ostfeld RS. Lyme Disease: The Ecology of a Complex System. New York, NY: Oxford University Press (2011). xii, 216 p.

111. Tsao JI. Reviewing molecular adaptations of Lyme borreliosis spirochetes in the context of reproductive fitness in natural transmission cycles. Vet Res (2009) 40(2):36. doi:10.1051/vetres/2009019

112. Levi T, Kilpatrick AM, Mangel M, Wilmers CC. Deer, predators, and the emergence of Lyme disease. Proc Natl Acad Sci U S A (2012) 109(27):10942-7. doi:10.1073/pnas.1204536109

113. Kurtenbach K, De Michelis S, Sewell HS, Etti S, Schafer SM, Holmes E, et al. The key roles of selection and migration in the ecology of Lyme borreliosis. Int J Med Microbiol (2002) 291(Suppl 33):152-4. doi:10.1016/S1438-4221(02)80029-7

114. Kurtenbach K, Hanincova K, Tsao JI, Margos G, Fish D, Ogden NH. Fundamental processes in the evolutionary ecology of Lyme borreliosis. Nat Rev Microbiol (2006) 4(9):660-9. doi:10.1038/nrmicro1475

115. Kurtenbach K, Sewell HS, Ogden NH, Randolph SE, Nuttall PA. Serum complement sensitivity as a key factor in Lyme disease ecology. Infect Immun (1998) 66(3):1248-51.
116. Brisson D, Brinkley C, Humphrey PT, Kemps BD, Ostfeld RS. It takes a community to raise the prevalence of a zoonotic pathogen. Interdiscip Perspect Infect Dis (2011) 2011:741406. doi:10.1155/2011/741406

117. Brisson D, Dykhuizen DE, Ostfeld RS. Conspicuous impacts of inconspicuous hosts on the Lyme disease epidemic. Proc Biol Sci (2008) 275(1631):227-35. doi:10.1098/rspb.2007.1208

118. Brisson D, Vandermause MF, Meece JK, Reed KD, Dykhuizen DE. Evolution of northeastern and midwestern Borrelia burgdorferi, United States. Emerg Infect Dis (2010) 16(6):911-7. doi:10.3201/eid1606.090329

119. Ogden NH, Bigras-Poulin M, Hanincová K, Maarouf A, O’Callaghan CJ, Kurtenbach K. Projected effects of climate change on tick phenology and fitness of pathogens transmitted by the North American tick Ixodes scapularis. J Theor Biol (2008) 254(3):621-32. doi:10.1016/j.jtbi.2008.06.020

120. Ogden NH, Bigras-Poulin M, O'Callaghan CJ, Barker IK, Lindsay LR, Maarouf A, et al. A dynamic population model to investigate effects of climate on geographic range and seasonality of the tick Ixodes scapularis. Int J Parasitol (2005) 35(4):375-89. doi:10.1016/j.ijpara.2004.12.013

121. Ogden NH, Maarouf A, Barker IK, Bigras-Poulin M, Lindsay LR, Morshed $\mathrm{MG}$, et al. Climate change and the potential for range expansion of the Lyme disease vector Ixodes scapularis in Canada. Int J Parasitol (2006) 36(1):63-70. doi:10.1016/j.ijpara.2005.08.016

122. Siembieda JL, Kock RA, McCracken TA, Newman SH. The role of wildlife in transboundary animal diseases. Anim Health Res Rev (2011) 12(1):95-111. doi:10.1017/S1466252311000041

123. Diuk-Wasser MA, Hoen AG, Cislo P, Brinkerhoff R, Hamer SA, Rowland $\mathrm{M}$, et al. Human risk of infection with Borrelia burgdorferi, the Lyme disease agent, in Eastern United States. Am J Trop Med Hyg (2012) 86(2):320-7. doi:10.4269/ajtmh.2012.11-0395

124. Pepin KM, Eisen RJ, Mead PS, Piesman J, Fish D, Hoen AG, et al. Geographic variation in the relationship between human Lyme disease incidence and density of infected host-seeking Ixodes scapularis nymphs in the Eastern United States. Am J Trop Med Hyg (2012) 86(6):1062-71. doi:10.4269/ajtmh.2012.11 0630

125. Center for Disease Control and Prevention. A CDC Framework for Preventing Infectious Diseases. Atlanta: CDC (2011).

126. CDC. Notice to readers: final 2012 reports of nationally notifiable infectious diseases. MMWR Morb Mortal Wkly Rep (2013) 62(33):669-82.

127. Gordillo G, Torres J, Solorzano F, Cedillo-Rivera R, Tapia-Conyer R, Munoz O. Serologic evidences suggesting the presence of Borrelia burgdorferi infection in Mexico. Arch Med Res (1999) 30(1):64-8. doi:10.1016/S0188-0128(98)00015-3

128. Gordillo-Pérez G, Torres J, Solórzano-Santos F, Garduño-Bautista V, TapiaConyer R, Muñóz O. Estudio seroepidemiológico de Borreliosis de Lyme en la Ciudad de México y el Noreste de la República Mexicana. Salud Pública Mex (2003) 45:351-5. doi:10.1590/S0036-36342003000500004

129. Gordillo-Perez G, Vargas M, Solorzano-Santos F, Rivera A, Polaco OJ, Alvarado L, et al. Demonstration of Borrelia burgdorferi sensu stricto infection in ticks from the northeast of Mexico. Clin Microbiol Infect (2009) 15(5):496-8. doi:10.1111/j.1469-0691.2009.02776.x

130. Martinez A, Salinas A, Martinez F, Cantu A, Miller DK. Serosurvey for selected disease agents in white-tailed deer from Mexico. J Wildl Dis (1999) 35(4):799-803. doi:10.7589/0090-3558-35.4.799

131. Gordillo-Pérez G, Vargas-Sandoval M, Sosa-Gutierrez C, Minero-Gonzalez E, Schoeder-Lima E, Parra-Montiel G, et al. Prevalencia de Infección de Borrelia burgdorferi y Ehrlichia spp en garrapatas y roedores provenientes de tres parques nacionales del Centro de la República Mexicana. Acarol Latinoam (2012) 1:291-5.

132. Illoldi-Rangel P, Rivaldi CL, Sissel B, Trout Fryxell R, Gordillo-Perez G, Rodriguez-Moreno A, et al. Species distribution models and ecological suitability analysis for potential tick vectors of Lyme disease in Mexico. J Trop Med (2012) 2012:959101. doi:10.1155/2012/959101

133. Gordillo-Perez G, Torres J, Solorzano-Santos F, de Martino S, Lipsker D, Velazquez E, et al. Borrelia burgdorferi infection and cutaneous Lyme disease, Mexico. Emerg Infect Dis (2007) 13(10):1556-8. doi:10.3201/eid1310.060630

134. Gordillo-Pérez MG, Solórzano-Santos F. Enfermedad de Lyme. Experiencia en niños mexicanos. Bol Méd Hosp Infant Méx (2010) 67:164-76.

135. Dumler JS, Barbet AF, Bekker CP, Dasch GA, Palmer GH, Ray SC, et al. Reorganization of genera in the families Rickettsiaceae and Anaplasmataceae in the order Rickettsiales: unification of some species of Ehrlichia with Anaplasma, 
Cowdria with Ehrlichia and Ehrlichia with Neorickettsia, descriptions of six new species combinations and designation of Ehrlichia equi and "HGE agent" as subjective synonyms of Ehrlichia phagocytophila. Int J Syst Evol Microbiol (2001) 51(Pt 6):2145-65. doi:10.1099/00207713-51-6-2145

136. Dantas-Torres F, Chomel BB, Otranto D. Ticks and tick-borne diseases: a one health perspective. Trends Parasitol (2012) 28(10):437-46. doi:10.1016/j.pt. 2012.07.003

137. Sosa-Gutierrez CG, Quintero Martinez MT, Gaxiola Camacho SM, Cota Guajardo S, Esteve-Gassent MD, Gordillo-Perez MG. Frequency and clinical epidemiology of canine monocytic ehrlichiosis in dogs infested with ticks from Sinaloa, Mexico. J Vet Med (2013) 2013:3. doi:10.1155/2013/797019

138. Chapman AS, Bakken JS, Folk SM, Paddock CD, Bloch KC, Krusell A, et al. Diagnosis and management of tickborne rickettsial diseases: Rocky Mountain spotted fever, ehrlichioses, and anaplasmosis - United States: a practical guide for physicians and other health-care and public health professionals. MMWR Recomm Rep (2006) 55(RR-4):1-27.

139. Bakken JS, Krueth J, Wilson-Nordskog C, Tilden RL, Asanovich K, Dumler JS. Clinical and laboratory characteristics of human granulocytic ehrlichiosis. JAMA (1996) 275(3):199-205. doi:10.1001/jama.1996.03530270039029

140. O’Reilly M, Paddock C, Elchos B, Goddard J, Childs J, Currie M. Physician knowledge of the diagnosis and management of Rocky Mountain spotted fever: Mississippi, 2002. Ann N Y Acad Sci (2003) 990:295-301. doi:10.1111/j.17496632.2003.tb07379.x

141. Eremeeva ME, Zambrano ML, Anaya L, Beati L, Karpathy SE, Santos-Silva MM, et al. Rickettsia rickettsii in Rhipicephalus ticks, Mexicali, Mexico. J Med Entomol (2011) 48(2):418-21. doi:10.1603/ME10181

142. Vargas M, Gordillo-Pérez G, Solórzano S, Rivera A, Polaco O, Muñoz O, et al. Evidences of Borrelia burgdorferi in ticks of the northeast of Mexico. Entomol $\operatorname{Mex}(2007)$ 6:830-5.

143. Olano JP, Masters E, Hogrefe W, Walker DH. Human monocytotropic ehrlichiosis, Missouri. Emerg Infect Dis (2003) 9(12):1579-86. doi:10.3201/eid0912. 020733

144. Carpenter CF, Gandhi TK, Kong LK, Corey GR, Chen SM, Walker DH, et al The incidence of ehrlichial and rickettsial infection in patients with unexplained fever and recent history of tick bite in central North Carolina. J Infect Dis (1999) 180(3):900-3. doi:10.1086/314954

145. Ojeda-Luna MD, Luna-Cervantes MD, Cruz-Canela L. Fiebre manchada. In: Epidemiológica. Veracruz: Secretaría de Salud (2014). p. 1-6.

146. Gongora-Biachi RA, Zavala-Velazquez J, Castro-Sansores CJ, GonzalezMartinez P. First case of human ehrlichiosis in Mexico. Emerg Infect Dis (1999) 5(3):481. doi:10.3201/eid0503.990327

147. Piesman J, Eisen L. Prevention of tick-borne diseases. Ann Rev Entomol (2008) 53:323-43. doi:10.1146/annurev.ento.53.103106.093429

148. Porretta D, Mastrantonio V, Amendolia S, Gaiarsa S, Epis S, Genchi C, et al. Effects of global changes on the climatic niche of the tick Ixodes ricinus inferred by species distribution modelling. Parasit Vectors (2013) 6:271. doi:10.1186/1756-3305-6-271

149. Brownstein JS, Holford TR, Fish D. A climate-based model predicts the spatial distribution of the Lyme disease vector Ixodes scapularis in the United States. Environ Health Perspect (2003) 111(9):1152-7. doi:10.1289/ehp.6052

150. Healy JA, Cross TF, Healy A. The alpha-Gpdh polymorphism in the tick Ixodes ricinus: similar diurnal trends in genotypic composition in Irish and Swedish population samples. Exp Appl Acarol (2004) 32(1-2):111-8. doi:10.1023/B:APPA.0000018198.83551.72

151. Adler B, de la Pena Moctezuma A. Leptospira and leptospirosis. Vet Microbiol (2010) 140(3-4):287-96. doi:10.1016/j.vetmic.2009.03.012

152. Desvars A, Cardinale E, Michault A. Animal leptospirosis in small tropical areas. Epidemiol Infect (2011) 139(2):167-88. doi:10.1017/S0950268810002074

153. Levett PN. Leptospirosis. Clin Microbiol Rev (2001) 14(2):296-326. doi:10. 1128/CMR.14.2.296-326.2001

154. Baverud V, Gunnarsson A, Engvall EO, Franzen P, Egenvall A. Leptospira seroprevalence and associations between seropositivity, clinical disease and host factors in horses. Acta Vet Scand (2009) 51:15. doi:10.1186/1751-0147-51-15

155. Kikuti M, Langoni H, Nobrega DN, Corrêa APFL, Ullmann LS. Occurrence and risk factors associated with canine leptospirosis. J Venom Anim Toxins Incl Trop Dis (2012) 18(1):124-7. doi:10.1590/S1678-91992012000100016

156. Oliveira Lavinsky M, Said RA, Strenzel GM, Langoni H. Seroprevalence of anti-Leptospira spp. antibodies in dogs in Bahia. Brazil. Prev Vet Med (2012) 106(1):79-84. doi:10.1016/j.prevetmed.2012.03.015
157. Prescott J. Canine leptospirosis in Canada: a veterinarian's perspective. CMAJ (2008) 178(4):397-8. doi:10.1503/cmaj.071092

158. Reis RB, Ribeiro GS, Felzemburgh RD, Santana FS, Mohr S, Melendez AX, et al. Impact of environment and social gradient on Leptospira infection in urban slums. PLoS Negl Trop Dis (2008) 2(4):e228. doi:10.1371/journal.pntd.0000228

159. Greene CE, editor. Laboratory diagnosis of canine leptospirosis and babesiosis. 24th Annual ACVIM Forum. Louisville, KY (2006).

160. Wasinski B, Dutkiewicz J. Leptospirosis - current risk factors connected with human activity and the environment. Ann Agric Environ Med (2013) 20(2):239-44

161. Bautista-Piña C, Romero-Salas D, García-Vázquez Z, López-De Buen L, CruzRomero A, Ortega-Santos JA, et al. Seroepidemiología de Leptospirosis en Cérvidos Exóticos del Municipio de Soto la Marina, Tamaulipas, México. I Simposium Internacional en Producción Agroalimentaria y XXIV Reunión CientíficaTecnológica Forestal y Agropecuaria. Villahermosa: Tabasco Memoria Científica (2012).

162. Espi A, Prieto JM, Alzaga V. Leptospiral antibodies in Iberian red deer (Cervus elaphus hispanicus), fallow deer (Dama dama) and European wild boar (Sus scrofa) in Asturias, Northern Spain. Vet J (2010) 183(2):226-7. doi:10.1016/j.tvjl.2008.10.003

163. Davidson WR, Crum JM, Blue JL, Sharp DW, Phillips JH. Parasites, diseases, and health status of sympatric populations of fallow deer and white-tailed deer in Kentucky. J Wildl Dis (1985) 21(2):153-9. doi:10.7589/0090-3558-21.2.153

164. Morse BW, Miller DL, Miller KV, Baldwin CA. Population health of fallow deer (Dama dama) on Little St. Simons Island, Georgia, USA. J Wildl Dis (2009) 45(2):411-21. doi:10.7589/0090-3558-45.2.411

165. New JC Jr, Wathen WG, Dlutkowski S. Prevalence of Leptospira antibodies in white-tailed deer, Cades Cove, Great Smoky Mountains National Park, Tennessee, USA. J Wildl Dis (1993) 29(4):561-7. doi:10.7589/0090-3558-29.4.561

166. Romero Salas D, Pérez de León AA. Bubalinocultura en Mexico: retos de industria pecuaria naciente. In: González Stagnaro C, Madrid Bury N, Soto Bellozo E, editors. Logros y Desafíos de la Ganadería Doble Propósito, 6ta ed. Maracaibo, VN: Fundación GIRARZ (2014). p. 707-15.

167. Romero SD, Cruz RA, García VZ, Montiel PF, Velázquez SF, Domínguez AG, et al. Seroprevalence and risk factors associated with Leptospirosis in water buffalo (Bubalus bubalis) in Veracruz, Mexico. XLIX Reunión Nacional de Investigación Pecuaria. Veracruz: Reuniones Nacionales de Investigación e Innovación Pecuaria, Agrícola, Forestal y Acuícola-Pesquera (2013).

168. Cruz RA, Romero-Salas D, Ahuja-Aguirre C, Aguilar-Domínguez M, BautistaPiña V. Frequency of canine leptospirosis in dog shelters in Veracruz, Mexico. Afr J Microbiol Res (2013) 7(16):1518-21. doi:10.5897/AJMR12.1053

169. Jimenez-Coello M, Vado-Solis I, Cardenas-Marrufo MF, Rodriguez-Buenfil JC, Ortega-Pacheco A. Serological survey of canine leptospirosis in the tropics of Yucatan Mexico using two different tests. Acta Trop (2008) 106(1):22-6. doi:10.1016/j.actatropica.2007.12.011

170. Billeter SA, Levy MG, Chomel BB, Breitschwerdt EB. Vector transmission of Bartonella species with emphasis on the potential for tick transmission. Med Vet Entomol (2008) 22(1):1-15. doi:10.1111/j.1365-2915.2008.00713.x

171. Bouchouicha R, Durand B, Monteil M, Chomel BB, Berrich M, Arvand M, et al. Molecular epidemiology of feline and human Bartonella henselae isolates. Emerg Infect Dis (2009) 15(5):813-6. doi:10.3201/eid1505.080995

172. Kosoy M, Hayman DT, Chan KS. Bartonella bacteria in nature: where does population variability end and a species start? Infect Genet Evol (2012) 12(5):894-904. doi:10.1016/j.meegid.2012.03.005

173. Tsai YL, Chang CC, Chuang ST, Chomel BB. Bartonella species and their ectoparasites: selective host adaptation or strain selection between the vector and the mammalian host? Comp Immunol Microbiol Infect Dis (2011) 34(4):299-314. doi:10.1016/j.cimid.2011.04.005

174. Tsai YL, Lin CC, Chomel BB, Chuang ST, Tsai KH, Wu WJ, et al. Bartonella infection in shelter cats and dogs and their ectoparasites. Vector Borne Zoonotic Dis (2011) 11(8):1023-30. doi:10.1089/vbz.2010.0085

175. McElroy KM, Blagburn BL, Breitschwerdt EB, Mead PS, McQuiston JH. Fleaassociated zoonotic diseases of cats in the USA: bartonellosis, flea-borne rickettsioses, and plague. Trends Parasitol (2010) 26(4):197-204. doi:10.1016/j.pt. 2010.01.001

176. Chomel BB, Kasten RW. Bartonellosis, an increasingly recognized zoonosis. JAppl Microbiol (2010) 109(3):743-50. doi:10.1111/J.1365-2672.2010.04679.X

177. Breitschwerdt EB, Maggi RG, Chomel BB, Lappin MR. Bartonellosis: an emerging infectious disease of zoonotic importance to animals and human beings. 
J Vet Emerg Crit Care (San Antonio) (2010) 20(1):8-30. doi:10.1111/J.14764431.2009.00496.X

178. Chomel BB, Boulouis HJ, Maruyama S, Breitschwerdt EB. Bartonella spp. in pets and effect on human health. Emerg Infect Dis (2006) 12(3):389-94. doi:10.3201/eid1205.050931

179. Hayman DT, McDonald KD, Kosoy MY. Evolutionary history of rat-borne Bartonella: the importance of commensal rats in the dissemination of bacterial infections globally. Ecol Evol (2013) 3(10):3195-203. doi:10.1002/ece3.702

180. Brouqui P. Arthropod-borne diseases associated with political and social disorder. Annu Rev Entomol (2011) 56:357-74. doi:10.1146/annurev-ento-120709144739

181. Brouqui P, Raoult D. Arthropod-borne diseases in homeless. Ann N Y Acad Sci (2006) 1078:223-35. doi:10.1196/annals.1374.041

182. Drali R, Sangare AK, Boutellis A, Angelakis E, Veracx A, Socolovschi C, et al. Bartonella quintana in body lice from scalp hair of homeless persons, France. Emerg Infect Dis (2014) 20(5):907-8. doi:10.3201/eid2005.131242

183. Foucault C, Brouqui P, Raoult D. Bartonella quintana characteristics and clinical management. Emerg Infect Dis (2006) 12(2):217-23. doi:10.3201/eid1202. 050874

184. Badiaga S, Brouqui P, Raoult D. Autochthonous epidemic typhus associated with Bartonella quintana bacteremia in a homeless person. Am J Trop Med Hyg (2005) 72(5):638-9.

185. Finkelstein JL, Brown TP, O’Reilly KL, Wedincamp J Jr, Foil LD. Studies on the growth of Bartonella henselae in the cat flea (Siphonaptera: Pulicidae). J Med Entomol (2002) 39(6):915-9. doi:10.1603/0022-2585-39.6.915

186. Dutta A, Schwarzwald HL, Edwards MS. Disseminated bartonellosis presenting as neuroretinitis in a young adult with human immunodeficiency virus infection. Pediatr Infect Dis J (2010) 29(7):675-7. doi:10.1097/INF. 0b013e3181d60a6d

187. Centers for Disease Control and Prevention. Cat-scratch disease in children - Texas, September 2000-August 2001. JAMA (2002) 287(20):2647-9. doi:10.1001/jama.287.20.2647-JWR0522-2-1

188. Laham FR, Kaplan SL. Hepatosplenic cat-scratch fever. Lancet Infect Dis (2008) 8(2):140. doi:10.1016/s1473-3099(08)70019-7

189. Shasha D, Gilon D, Vernea F, Moses AE, Strahilevitz J. Visceral cat scratch disease with endocarditis in an immunocompetent adult: a case report and review of the literature. Vector Borne Zoonotic Dis (2014) 14(3):175-81. doi:10.1089/vbz.2012.1279

190. Huarcaya E, Maguina C, Best I, Solorzano N, Leeman L. Immunological response in cases of complicated and uncomplicated bartonellosis during pregnancy. Rev Inst Med Trop Sao Paulo (2007) 49(5):335-7. doi:10.1590/S003646652007000500012

191. Karris MY, Litwin CM, Dong HS, Vinetz J. Bartonella henselae infection of prosthetic aortic valve associated with colitis. Vector Borne Zoonotic Dis (2011) 11(11):1503-5. doi:10.1089/vbz.2010.0169

192. Reeves WK, Rogers TE, Dasch GA. Bartonella and Rickettsia from fleas (Siphonaptera: Ceratophyllidae) of prairie dogs (Cynomys spp.) from the western United States. J Parasitol (2007) 93(4):953-5. doi:10.1645/ge-1111r1.1

193. Schaefer JD, Moore GM, Namekata MS, Kasten RW, Chomel BB. Seroepidemiology of Bartonella infection in gray foxes from Texas. Vector Borne Zoonotic Dis (2012) 12(5):428-30. doi:10.1089/vbz.2011.0805

194. Hamer SA, Tsao JI, Walker ED, Mansfield LS, Foster ES, Hickling GJ. Use of tick surveys and serosurveys to evaluate pet dogs as a sentinel species for emerging Lyme disease. Am J Vet Res (2009) 70(1):49-56. doi:10.2460/ajvr.70.1.49

195. Little SE, Heise SR, Blagburn BL, Callister SM, Mead PS. Lyme borreliosis in dogs and humans in the USA. Trends Parasitol (2010) 26(4):213-8. doi:10.1016/j.pt.2010.01.006

196. Mead P, Goel R, Kugeler K. Canine serology as adjunct to human Lyme disease surveillance. Emerg Infect Dis (2011) 17(9):1710-2. doi:10.3201/eid1709. 110210

197. Zangwill KM. Cat scratch disease and other Bartonella infections. Adv Exp Med Biol (2013) 764:159-66. doi:10.1007/978-1-4614-4726-9_13

198. Perez de Leon AA, Teel PD, Auclair AN, Messenger MT, Guerrero FD, Schuster $\mathrm{G}$, et al. Integrated strategy for sustainable cattle fever tick eradication in USA is required to mitigate the impact of global change. Front Physiol (2012) 3:195. doi:10.3389/fphys.2012.00195

199. Prasad KJ. Emerging and re-merging parasitic diseases. J Int Med Sci Acad (2010) 23:45-50.
200. Schnittger L, Rodriguez AE, Florin-Christensen M, Morrison DA. Babesia: a world emerging. Infect Genet Evol (2012) 12(8):1788-809. doi:10.1016/j. meegid.2012.07.004

201. Kirby CS III, Williams SC, Magnarelli LA, Bharadwaj A, Ertel SH, Nelson RS. Expansion of zoonotic babesiosis and reported human cases, Connecticut, 2001-2010. J Med Entomol (2014) 51(1):245-52. doi:10.1603/ME13154

202. Vannier E, Krause PJ. Update on babesiosis. Interdiscip Perspect Infect Dis (2009) 2009:984568. doi:10.1155/2009/984568

203. Pérez de León AA, Vannier E, Almazán C, Krause PJ. Tick-borne protozoa. 2nd ed. In: Sonenhine DE, Roe RM, editors. Biology of Ticks (Vol. 2), New York, NY: Oxford University Press (2014). p. 147-79.

204. Gray J, Zintl A, Hildebrandt A, Hunfeld KP, Weiss L. Zoonotic babesiosis: overview of the disease and novel aspects of pathogen identity. Ticks Tick Borne Dis (2010) 1(1):3-10. doi:10.1016/j.ttbdis.2009.11.003

205. Osorno BM, Vega C, Ristic M, Robles C, Ibarra S. Isolation of Babesia spp from asymptomatic human beings. Vet Parasitol (1976) 2(1):111-20. doi:10.1016/0304-4017(76)90057-1

206. Colwell DD, Dantas-Torres F, Otranto D. Vector-borne parasitic zoonoses: emerging scenarios and new perspectives. Vet Parasitol (2011) 182(1):14-21. doi:10.1016/j.vetpar.2011.07.012

207. Healy G. The impact of cultural and environmental changes on the epidemiology and control of human babesiosis. Trans R Soc Trop Med Hyg (1989) 83(Suppl):35-8. doi:10.1016/0035-9203(89)90601-9

208. Zanet S, Trisciuoglio A, Bottero E, de Mera IG, Gortazar C, Carpignano MG, et al. Piroplasmosis in wildlife: Babesia and Theileria affecting free-ranging ungulates and carnivores in the Italian Alps. Parasit Vectors (2014) 7:70. doi:10.1186/1756-3305-7-70

209. Olmeda AS, Armstrong PM, Rosenthal BM, Valladares B, del Castillo A, de Armas F, et al. A subtropical case of human babesiosis. Acta Trop (1997) 67(3):229-34. doi:10.1016/S0001-706X(97)00045-4

210. Senanayake SN, Paparini A, Latimer M, Andriolo K, Dasilva AJ, Wilson H, et al. First report of human babesiosis in Australia. Med J Aust (2012) 196(5):350-2. doi:10.5694/mjal1.11378

211. Rodríguez-Morales AJ. Epidemiología de la babesiosis: zoonosis emergente. Acta Cient Estud (2007) 5:132-8.

212. Rios L, Alvarez G, Blair S. Serological and parasitological study and report of the first case of human babesiosis in Colombia. Rev Soc Bras Med Trop (2003) 36(4):493-8. doi:10.1590/S0037-86822003000400010

213. Aliota MT, Dupuis AP II, Wilczek MP, Peters RJ, Ostfeld RS, Kramer LD. The prevalence of zoonotic tick-borne pathogens in Ixodes scapularis collected in the Hudson Valley, New York State. Vector Borne Zoonotic Dis (2014) 14(4):245-50. doi:10.1089/vbz.2013.1475

214. Prusinski MA, Kokas JE, Hukey KT, Kogut SJ, Lee J, Backenson PB. Prevalence of Borrelia burgdorferi (Spirochaetales: Spirochaetaceae), Anaplasma phagocytophilum (Rickettsiales: Anaplasmataceae), and Babesia microti (Piroplasmida: Babesiidae) in Ixodes scapularis (Acari: Ixodidae) collected from recreational lands in the Hudson Valley Region, New York State. J Med Entomol (2014) 51(1):226-36. doi:10.1603/ME13101

215. López R, Montenegro-James S, Toro M. Seroprevalencia de la babesiosis humana en Venezuela. Vet Trop (1988) 13:93-101.

216. Suárez-Hernández M, Alonso Castellano M, Peláez Martínez R, Sánchez Pérez B, Bravo González JR, Sánchez Sibello A. Pesquisaje de Babesia en trabajadores agropecuarios y donantes en la provincia de Ciego de Ávila. Rev Cubana Med Trop (1997) 49:130-5.

217. Estrada-Pena A, Ostfeld RS, Peterson AT, Poulin R, de la Fuente J. Effects of environmental change on zoonotic disease risk: an ecological primer. Trends Parasitol (2014) 30(4):205-14. doi:10.1016/j.pt.2014.02.003

218. Diuk-Wasser MA, Liu Y, Steeves TK, Folsom-O’Keefe C, Dardick KR, Lepore T, et al. Monitoring human babesiosis emergence through vector surveillance new England, USA. Emerg Infect Dis (2014) 20(2):225-31. doi:10.3201/ eid1302/130644

219. Sherr VT. Human babesiosis - an unrecorded reality. Absence of formal registry undermines its detection, diagnosis and treatment, suggesting need for immediate mandatory reporting. Med Hypotheses (2004) 63(4):609-15. doi:10.1016/j.mehy.2004.04.006

220. Telford SR III, Goethert HK. Emerging tick-borne infections: rediscovered and better characterized, or truly "new"? Parasitology (2004) 129(Suppl):S301-27. doi:10.1017/S0031182003004669 
221. Hildebrandt A, Hunfeld KP. Human babesiosis - a rare but potentially dangerous zoonosis. Dtsch Med Wochenschr (2014) 139(18):957-62. doi:10.1055/ s-0034- 1369936

222. Yabsley MJ, Shock BC. Natural history of zoonotic: role of wildlife reservoirs. Int J Parasitol Parasites Wildl (2013) 2:18-31. doi:10.1016/j.ijppaw.2012.11.003

223. Clark K, Savick K, Butler J. Babesia microti in rodents and raccoons from Northeast Florida. J Parasitol (2012) 98(6):1117-21. doi:10.1645/GE-3083.1

224. Blanton JD, Self J, Niezgoda M, Faber ML, Dietzschold B, Rupprecht C. Oral vaccination of raccoons (Procyon lotor) with genetically modified rabies virus vaccines. Vaccine (2007) 25(42):7296-300. doi:10.1016/j.vaccine.2007.08.004

225. Bradley RD, Henson DD, Durish ND. Re-evaluation of the geographic distribution and phylogeography of the Sigmodon hispidus complex based on mitochondrial DNA sequences. Southwest Nat (2008) 53(3):301-10. doi:10.1894/ MRD-03.1

226. Guzman-Cornejo C, Robbins RG, Perez TM. The Ixodes (Acari: Ixodidae) of Mexico: parasite-host and host-parasite checklists. Zootaxa (2007) 1553:47-58

227. Darsie RF, Anastos G. Geographical distribution and hosts of Ixodes texanus banks (Acarina, Ixodidae). Ann Entomol Soc Am (1957) 50:295-301.

228. Yunker CE, Keirans JE, Clifford CM, Easton ER. Dermacentor ticks (Acari: Ixodoidea: Ixodidae) of the new world: a scanning electron microscope atlas. Proc Entomol Soc Wash (1986) 88:609-27.

229. Clark KL, Oliver JH Jr, Grego JM, James AM, Durden LA, Banks CW. Host associations of ticks parasitizing rodents at Borrelia burgdorferi enzootic sites in South Carolina. J Parasitol (2001) 87(6):1379-86. doi:10.2307/3285304

230. Durden LA, Hu R, Oliver JH Jr, Cilek JE. Rodent ectoparasites from two locations in Northwestern Florida. J Vector Ecol (2000) 25(2):222-8.

231. Shock BC, Moncayo A, Cohen S, Mitchell EA, Williamson PC, Lopez G, et al. Diversity of piroplasms detected in blood-fed and questing ticks from several states in the United States. Ticks Tick Borne Dis (2014) 5(4):373-80. doi:10.1016/j.ttbdis.2014.01.003

232. Stromdahl EY, Hickling GJ. Beyond Lyme: aetiology of tick-borne human diseases with emphasis on the South-Eastern United States. Zoonoses Public Health (2012) 59(Suppl 2):48-64. doi:10.1111/j.1863-2378.2012.01475.x

233. Charles RA, Kjos S, Ellis AE, Dubey JP, Shock BC, Yabsley MJ. Parasites and vector-borne pathogens of southern plains woodrats (Neotoma micropus) from Southern Texas. Parasitol Res (2012) 110(5):1855-62. doi:10.1007/s00436-0112710-z

234. Merten HA, Durden LA. A state-by-state survey of ticks recorded from humans in the United States. J Vector Ecol (2000) 25(1):102-13.

235. Guzmán-Cornejo C, Robbins RG, Guglielmone AA, Montiel-Parra G, Pérez TM. The amblyomma (Acari: Ixodida: Ixodidae) of Mexico: identification keys, distribution and hosts. Zootaxa (2011) 2998:16-38.

236. Prince HE, Lape-Nixon M, Patel H, Yeh C. Comparison of the Babesia duncani (WA1) IgG detection rates among clinical sera submitted to a reference laboratory for WA1 IgG testing and blood donor specimens from diverse geographic areas of the United States. Clin Vaccine Immunol (2010) 17(11):1729-33 doi:10.1128/CVI.00256-10

237. Holman PJ, Backlund BB, Wilcox AL, Stone R, Stricklin AL, Bardin KE. Detection of a large unnamed Babesia piroplasm originally identified in dogs in North Carolina in a dog with no history of travel to that state. J Am Vet Med Assoc (2009) 235(7):851-4. doi:10.2460/javma.235.7.851

238. Leger E, Vourc'h G, Vial L, Chevillon C, McCoy KD. Changing distributions of ticks: causes and consequences. Exp Appl Acarol (2013) 59(1-2):219-44. doi:10.1007/s10493-012-9615-0

239. Swanson SJ, Neitzel D, Reed KD, Belongia EA. Coinfections acquired from Ixodes ticks. Clin Microbiol Rev (2006) 19(4):708-27. doi:10.1128/CMR. 00011-06

240. Zhou X, Li SG, Chen SB, Wang JZ, Xu B, Zhou HJ, et al. Co-infections with Babesia microti and Plasmodium parasites along the China-Myanmar border Infect Dis Poverty (2013) 2(1):24. doi:10.1186/2049-9957-2-24

241. Perez de Leon AA, Strickman DA, Knowles DP, Fish D, Thacker E, de la Fuente J, et al. One Health approach to identify research needs in bovine and human babesioses: workshop report. Parasit Vectors (2010) 3(1):36. doi:10.1186/1756-3305-3-36

242. Esch KJ, Petersen CA. Transmission and epidemiology of zoonotic protozoal diseases of companion animals. Clin Microbiol Rev (2013) 26(1):58-85 doi:10.1128/CMR.00067-12
243. Oliveira F, de Carvalho AM, de Oliveira CI. Sand-fly saliva-Leishmania-man the trigger trio. Front Immunol (2013) 4:375. doi:10.3389/fimmu.2013.00375

244. WHO. Leishmaniasis: Epidemiology and Access to Medicines. Geneva: WHO (2012).

245. WHO. World Health Organization working to overcome the global impact of neglected tropical disease. First WHO Report on Neglected Disease. Geneva: World Health Organization (2010).

246. Kobets T, Grekov I, Lipoldova M. Leishmaniasis: prevention, parasite detection and treatment. Curr Med Chem (2012) 19(10):1443-74. doi:10.2174/ 092986712799828300

247. Strazzulla A, Cocuzza S, Pinzone MR, Postorino MC, Cosentino S, Serra A, et al. Mucosal leishmaniasis: an underestimated presentation of a neglected disease. Biomed Res Int (2013) 2013:805108. doi:10.1155/2013/ 805108

248. Lessa MM, Lessa HA, Castro TW, Oliveira A, Scherifer A, Machado P, et al. Mucosal leishmaniasis: epidemiological and clinical aspects. Braz J Otorhinolaryngol (2007) 73(6):843-7.

249. Ready PD. Epidemiology of visceral leishmaniasis. Clin Epidemiol (2014) 6:147-54. doi:10.2147/clep.s44267

250. Trainor KE, Porter BF, Logan KS, Hoffman RJ, Snowden KF. Eight cases of feline cutaneous leishmaniasis in Texas. Vet Pathol (2010) 47(6):1076-81. doi:10.1177/0300985810382094

251. Seidelin H. Leishmaniasis and babesiasis in Yucatán. Ann Trop Med Parasitol (1912) 6:295-9.

252. Beltrán E, Bustamante ME. Datos epidemiológicos acerca de la úlcera de los chicleros (Leishmania americana) en México. Rev Inst Salubr Enferm Trop (1942) 3:1-28.

253. Biagi F, Lopez R, De Biagi AM. Kala-azar in Mexico; and ecological problem from study. Rev Inst Salubr Enferm Trop (1965) 25(1):3-12.

254. Pastor-Santiago JA, Chavez-Lopez S, Guzman-Bracho C, Flisser A, Olivo-Diaz A. American visceral leishmaniasis in Chiapas, Mexico. Am J Trop Med Hyg (2012) 86(1):108-14. doi:10.4269/ajtmh.2012.10-0561

255. Wright NA, Davis LE, Aftergut KS, Parrish CA, Cockerell CJ. Cutaneous leishmaniasis in Texas: a northern spread of endemic areas. J Am Acad Dermatol (2008) 58(4):650-2. doi:10.1016/j.jaad.2007.11.008

256. Clarke CF, Bradley KK, Wright JH, Glowicz J. Case report: emergence of autochthonous cutaneous leishmaniasis in Northeastern Texas and Southeastern Oklahoma. Am J Trop Med Hyg (2013) 88(1):157-61. doi:10.4269/ajtmh. 2012.11-0717

257. Arjona-Jimenez G, Villegas N, Lopez-Cespedes A, Marin C, Longoni SS, BolioGonzalez ME, et al. Prevalence of antibodies against three species of Leishmania (L. mexicana, L. braziliensis, L. infantum) and possible associated factors in dogs from Merida, Yucatan, Mexico. Trans R Soc Trop Med Hyg (2012) 106:252-8. doi:10.1016/j.trstmh.2011.12.003

258. Longoni SS, Lopez-Cespedes A, Sanchez-Moreno M, Bolio-Gonzalez ME Sauri-Arceo CH, Rodriguez-Vivas RI, et al. Detection of different Leishmania spp. and Trypanosoma cruzi antibodies in cats from the Yucatan Peninsula (Mexico) using an iron superoxide dismutase excreted as antigen. Comp Immunol Microbiol Infect Dis (2012) 35(5):469-76. doi:10.1016/j.cimid.2012. 04.003

259. Pagliano P, Carannante N, Rossi M, Gramiccia M, Gradoni L, Faella FS, et al. Visceral leishmaniasis in pregnancy: a case series and a systematic review of the literature. J Antimicrob Chemother (2005) 55(2):229-33. doi:10.1093/jac/ dkh538

260. Jeronimo SM, de Queiroz Sousa A, Pearson RD. Leishmaniasis. 2nd ed. In: Guerrant RL, Walker DH, Weller PF, editors. Tropical Infectious Diseases. Philadelphia, PA: Churchill Livingston Inc (2006). p. 1095-2107.

261. Herwalt BL. Leishmaniasis. 17th ed. In: Kasper DLBE, Fauci AS, Hauser SL, Longo DL, Jameson JL, editors. Harrison's Principles of Internal Medicine. New York, NY: McGraw-Hill (2006). p. 1095-2107.

262. Nascimento ET, Moura ML, Queiroz JW, Barroso AW, Araujo AF, Rego EF, et al. The emergence of concurrent HIV-1/AIDS and visceral leishmaniasis in Northeast Brazil. Trans R Soc Trop Med Hyg (2011) 105(5):298-300. doi:10.1016/j.trstmh.2011.01.006

263. Duprey ZH, Steurer FJ, Rooney JA, Kirchhoff LV, Jackson JE, Rowton ED, et al. Canine visceral leishmaniasis, United States and Canada, 2000-2003. Emerg Infect Dis (2006) 12(3):440-6. doi:10.3201/eid1205.050811 
264. Kerr SF, McHugh CP, Dronen NO Jr. Leishmaniasis in Texas: prevalence and seasonal transmission of Leishmania mexicana in Neotoma micropus. Am J Trop Med Hyg (1995) 53(1):73-7.

265. Pech-May A, Escobedo-Ortegon FJ, Berzunza-Cruz M, Rebollar-Tellez EA. Incrimination of four sandfly species previously unrecognized as vectors of Leishmania parasites in Mexico. Med Vet Entomol (2010) 24(2):150-61. doi:10.1111/j.1365-2915.2010.00870.x

266. McHugh CP, Melby PC, LaFon SG. Leishmaniasis in Texas: epidemiology and clinical aspects of human cases. Am J Trop Med Hyg (1996) 55(5):547-55.

267. McHugh CP, Grogl M, Kreutzer RD. Isolation of Leishmania mexicana (Kinetoplastida: Trypanosomatidae) from Lutzomyia anthophora (Diptera: Psychodidae) collected in Texas. J Med Entomol (1993) 30(3):631-3.

268. Young DG, Perkins PV. Phlebotomine sand flies of North America (Diptera: Psychodidae). Mosq News (1984) 44:263-304.

269. Endris RG, Young DG, Perkins PV. Experimental transmission of Leishmania mexicana by a North American sand fly, Lutzomyia anthophora (Diptera: Psychodidae). J Med Entomol (1987) 24(2):243-7.

270. Rosete-Ortíz D, Berzunza-Cruz MS, Salaiza-Suazo NL, González C, TreviñoGarza N, Ruiz-Remigio A, et al. Canine leishmaniasis in Mexico: the detection of a new focus of canine leishmaniasis in the state of Guerrero correlates with an increase of human cases. Bol Med Hosp Infant Mex (2011) 68(2):88-93.

271. Moo-Llanes D, Ibarra-Cerdena CN, Rebollar-Tellez EA, Ibanez-Bernal S, Gonzalez C, Ramsey JM. Current and future niche of North and Central American sand flies (Diptera: Psychodidae) in climate change scenarios. PLoS Negl Trop Dis (2013) 7(9):e2421. doi:10.1371/journal.pntd.0002421

272. Monroy-Ostria A, Hernandez-Montes O, Barker DC. Aetiology of visceral leishmaniasis in Mexico. Acta Trop (2000) 75(2):155-61. doi:10.1016/S0001706X(99)00055-8

273. Palatnik-de-Sousa CB, Day MJ. One Health: the global challenge of epidemic and endemic leishmaniasis. Parasit Vectors (2011) 4:197. doi:10.1186/17563305-4-197

274. Roberts LS, Janovy J Jr. Foundations of Parasitology. 8th ed. Whitby: McGrawHill Ryerson (2009).

275. Kirchhoff L. Current public health concerns. In: Tyler KM, Miles MA, editors. American Trypanosomiasis. Dordrecht: Kluwer (2003). p. 157-62.

276. Rodrigues Coura J, Viñas PA. Chagas disease: a new worldwide challenge. Nature (2010) 465:S6-7. doi:10.1038/nature09221

277. Sarkar S, Strutz SE, Frank DM, Rivaldi CL, Sissel B, Sánchez-Cordero V. Chagas disease risk in Texas. PLoS Negl Trop Dis (2010) 4(10):e836. doi:10.1371/ journal.pntd.0000836

278. Ramsey JM, Gutiérrez-Cabrera AE, Salgado-Ramírez L, Peterson AT, SánchezCordero V, Ibarra-Cerdeña CN. Ecological connectivity of Trypanosoma cruzi reservoirs and Triatoma pallidipennis hosts in an anthropogenic landscape with endemic Chagas disease. PLoS One (2012) 7(9):e46013. doi:10.1371/journal. pone. 0046013

279. Prata A. Clinical and epidemiological aspects of Chagas disease. Lancet Infect Dis (2001) 1(2):92-100. doi:10.1016/S1473-3099(01)00065-2

280. Bern C, Kjos S, Yabsley MJ, Montgomery SP. Trypanosoma cruzi and Chagas' disease in the United States. Clin Microbiol Rev (2011) 24(4):655-81. doi:10.1128/CMR.00005-11

281. Reinhard K, Fink TM, Skiles J. A case of megacolon in Rio Grande valley as a possible case of Chagas disease. Mem Inst Oswaldo Cruz (2003) 98(Suppl 1):165-72. doi:10.1590/S0074-02762003000900025

282. Barth E, Kundrotas L. Megacolon from Chagas disease in an ancient Texan. Diagnosis: Chagas disease causing mega-disease, in this case megacolon. Gastroenterology (2011) 141(1):35-404. doi:10.1053/j.gastro.2010.06.077

283. Leiby DA, Herron RM Jr, Garratty G, Herwaldt BL. Trypanosoma cruzi parasitemia in US blood donors with serologic evidence of infection. J Infect Dis (2008) 198(4):609-13. doi:10.1086/590159

284. Hanford EJ, Zhan FB, Lu Y, Giordano A. Chagas disease in Texas: recognizing the significance and implications of evidence in the literature. Soc Sci Med (2007) 65(1):60-79. doi:10.1016/j.socscimed.2007.02.041

285. Bern C, Montgomery SP. An estimate of the burden of Chagas disease in the United States. Clin Infect Dis (2009) 49(5):e52-4. doi:10.1086/605091

286. Dumonteil E. Update on Chagas' disease in Mexico. Salud Pública Mex (1999) 41(4):322-7.

287. Carabarin-Lima A, Gonzalez-Vazquez MC, Rodriguez-Morales O, BaylonPacheco L, Rosales-Encina JL, Reyes-Lopez PA, et al. Chagas disease (American trypanosomiasis) in Mexico: an update. Acta Trop (2013) 127(2):126-35. doi:10.1016/j.actatropica.2013.04.007

288. Guzman-Bracho C. Epidemiology of Chagas disease in Mexico: an update. Trends Parasitol (2001) 17(8):372-6. doi:10.1016/S1471-4922(01)01952-3

289. Martínez-Tovar JG, Fernández-Salas I, Rebollar-Téllez AE. Chagas chronic cardiomyopathy: report of two cases in Coahuila, Mexico. Int J Case Rep Images (2014) 5(8):533-7. doi:10.5348/ijcri-201459-CS- 10045

290. Martinez-Tovar JG, Rebollar-Tellez EA, Fernandez Salas I. Seroprevalence of T. cruzi infection in blood donors and Chagas cardiomyopathy in patients from the coal mining region of Coahuila, Mexico. Rev Inst Med Trop Sao Paulo (2014) 56(2):169-74. doi:10.1590/S0036-46652014000200014

291. Martínez-Tovar JG, Rodríguez-Rojas JJ, Arque-Chunga W, Lozano-Rendón JA, Ibarra-Juárez LA, Dávila-Barboza JA, et al. Nuevos registros geográficos y notas de infección de Triatoma gerstaeckeri (Stål) y Triatoma rubida (Uhler) (Hemiptera: Reduviidae: Triatominae) en Nuevo León y Coahuila, Mexico. Acta Zool Mex (2013) 29(1):227-33.

292. Monteon-Padilla VM, Hernandez-Becerril N, Guzman-Bracho C, RosalesEncina JL, Reyes-Lopez PA. American trypanosomiasis (Chagas' disease) and blood banking in Mexico City: seroprevalence and its potential transfusional transmission risk. Arch Med Res (1999) 30(5):393-8. doi:10.1016/S01884409(99)00062-4

293. WHO. Control of Chagas Disease. Geneva: World Health Organization (2002). $109 \mathrm{p}$.

294. Lopez-Cespedes A, Longoni SS, Sauri-Arceo CH, Rodriguez-Vivas RI, Villegas N, Escobedo-Ortegon J, et al. Seroprevalence of antibodies against the excreted antigen superoxide dismutase by Trypanosoma cruzi in dogs from the Yucatan Peninsula (Mexico). Zoonoses Public Health (2013) 60(4):277-83. doi:10.1111/j.1863-2378.2012.01520.x

295. Kjos SA, Snowden KF, Craig TM, Lewis B, Ronald N, Olson JK. Distribution and characterization of canine Chagas disease in Texas. Vet Parasitol (2008) 152(3-4):249-56. doi:10.1016/j.vetpar.2007.12.021

296. Estrada-Franco JG, Bhatia V, Diaz-Albiter H, Ochoa-Garcia L, Barbabosa A, Vazquez-Chagoyan JC, et al. Human Trypanosoma cruzi infection and seropositivity in dogs, Mexico. Emerg Infect Dis (2006) 12(4):624-30. doi:10.3201/ eid1204.050450

297. Tenney TD, Curtis-Robles R, Snowden KF, Hamer SA. Shelter dogs as sentinels for Trypanosoma cruzi transmission across Texas. Emerg Infect Dis (2014) 20(8):1323-6. doi:10.3201/eid2008.131843

298. Ibarra-Cerdena CN, Sanchez-Cordero V, Townsend Peterson A, Ramsey JM. Ecology of North American Triatominae. Acta Trop (2009) 110(2-3):178-86. doi:10.1016/j.actatropica.2008.11.012

299. Medina-Torres I, Vazquez-Chagoyan JC, Rodriguez-Vivas RI, de Oca-Jimenez RM. Risk factors associated with triatomines and its infection with Trypanosoma cruzi in rural communities from the southern region of the state of Mexico, Mexico. Am J Trop Med Hyg (2010) 82(1):49-54. doi:10.4269/ajtmh 2010.08-0624

300. Cruz-Reyes A, Pickering-Lopez JM. Chagas disease in Mexico: an analysis of geographical distribution during the past 76 years - a review. Mem Inst Oswaldo Cruz (2006) 101(4):345-54. doi:10.1590/S0074-02762006000400001

301. Reyes-Novelo E, Ruiz-Pina H, Escobedo-Ortegon J, Barrera-Perez M, Manrique-Saide P, Rodriguez-Vivas RI. Triatoma dimidiata (Latreille) abundance and infection with Trypanosoma cruzi in a rural community of Yucatan, Mexico. Neotrop Entomol (2013) 42(3):317-24. doi:10.1007/s13744013-0120-x

302. Abad-Franch F, Vega MC, Rolón MS, Santos WS, Rojas de Arias A. Community participation in Chagas disease vector surveillance: systematic review. PLoS Negl Trop Dis (2011) 5(6):e1207. doi:10.1371/journal.pntd.0001207

303. Ramsey JM, Gutierrez-Cabrera AE, Salgado-Ramirez L, Peterson AT, SanchezCordero V, Ibarra-Cerdena CN. Ecological connectivity of Trypanosoma cruzi reservoirs and Triatoma pallidipennis hosts in an anthropogenic landscape with endemic Chagas disease. PLoS One (2012) 7(9):e46013. doi:10.1371/journal. pone. 0046013

304. Sarkar S, Strutz SE, Frank DM, Rivaldi CL, Sissel B, Sanchez-Cordero V. Chagas disease risk in Texas. PLoS Negl Trop Dis (2010) 4(10):e836. doi:10.1371/ journal.pntd.0000836

305. Carcavallo RU, Casas SC. Some health impacts of global warming in South America: vector-borne diseases. J Epidemiol (1996) 6(4):153. doi:10.2188/jea. 6.4sup_153 
306. Intergovernmental Panel on Climate Change. Climate change 2001: synthesis report. A contribution of working groups I, II, and III to the third assessment report of the intergovernmental panel on climate change. In: Watson RT, The Core Writing Team, editors. Intergovernmental Panel on Climate Change. Cambridge: Cambridge University Press (2001). 398 p.

307. Asin S, Catala S. Development of Trypanosoma cruzi in Triatoma infestans: influence of temperature and blood consumption. J Parasitol (1995) 81(1):1-7. doi: $10.2307 / 3283997$

Conflict of Interest Statement: The authors declare that the research was conducted in the absence of any commercial or financial relationships that could be construed as a potential conflict of interest.

Received: 29 June 2014; accepted: 19 September 2014; published online: 17 November 2014.
Citation: Esteve-Gassent MD, Pérez de León AA, Romero-Salas D, Feria-Arroyo TP, Patino R, Castro-Arellano I, Gordillo-Pérez G, Auclair A, Goolsby J, Rodriguez-Vivas RI and Estrada-Franco JG (2014) Pathogenic landscape of transboundary zoonotic diseases in the Mexico-US border along the Rio Grande. Front. Public Health 2:177. doi: $10.3389 /$ fpubh.2014.00177

This article was submitted to Epidemiology, a section of the journal Frontiers in Public Health.

Copyright (c) 2014 Esteve-Gassent, Pérez de León, Romero-Salas, Feria-Arroyo, Patino, Castro-Arellano, Gordillo-Pérez, Auclair, Goolsby, Rodriguez-Vivas and EstradaFranco. This is an open-access article distributed under the terms of the Creative Commons Attribution License (CC BY). The use, distribution or reproduction in other forums is permitted, provided the original author(s) or licensor are credited and that the original publication in this journal is cited, in accordance with accepted academic practice. No use, distribution or reproduction is permitted which does not comply with these terms. 